\title{
Social Risk, Fiscal Risk, and the Portfolio of Government Programs
}

\section{Citation}

Hanson, Samuel G., David S. Scharfstein, and Adi Sunderam. "Social Risk, Fiscal Risk, and the Portfolio of Government Programs." Review of Financial Studies (June 2019)

\section{Permanent link}

http://nrs.harvard.edu/urn-3:HUL.InstRepos:38035039

\section{Terms of Use}

This article was downloaded from Harvard University's DASH repository, and is made available under the terms and conditions applicable to Open Access Policy Articles, as set forth at http:// nrs.harvard.edu/urn-3:HUL.InstRepos:dash.current.terms-of-use\#OAP

\section{Share Your Story}

The Harvard community has made this article openly available.

Please share how this access benefits you. Submit a story.

\section{Accessibility}




\title{
Social Risk, Fiscal Risk, and the Portfolio of Government Programs*
}

\author{
Samuel G. Hanson \\ David S. Scharfstein \\ Harvard Business School
}

Adi Sunderam

June 2018

\begin{abstract}
We develop a model of government portfolio choice in which a benevolent government chooses the scale of risky projects in the presence of market failures and tax distortions. These two frictions generate motives to manage social risk and fiscal risk. Social risk management makes attractive programs that ameliorate market failures in bad economic times. Fiscal risk management makes unattractive programs that entail large government outlays at times when other programs in the government's portfolio also require large outlays. We characterize the determinants of social and fiscal risk and argue that these two risk management motives often conflict. Using the model, we explore how the attractiveness of different financial stability programs varies with the government's fiscal burden and with characteristics of the economy.
\end{abstract}

${ }^{*}$ Corresponding author: Adi Sunderam, Harvard Business School, Baker Library 359, Boston, MA 02163, asunderam@hbs.edu, (617) 495-6644. We thank Andy Abel, John Campbell, George Constantinides, Eduardo Davilla, Itay Goldstein (editor), Martin Oehmke, Guillermo Ordonez, Thomas Philippon, Julio Rotemberg, Jeremy Stein, Matt Weinzierl, three anonymous referees and seminar participants at Columbia, Chicago, Duke, Harvard, Kellogg, NYU, Princeton, Wharton, and the NBER Corporate Finance Summer Institute for helpful comments. We gratefully acknowledge funding from the Harvard Business School Division of Research. 


\section{Introduction}

In modern economies, a significant fraction of economy-wide risk is borne indirectly by taxpayers via the government. Governments have significant explicit and implicit liabilities associated with retirement benefits, social insurance programs, and financial system backstops. These liabilities are large: the amount of credit risk explicitly recognized on the U.S. government balance sheet exceeds $\$ 3$ trillion, while off-balance sheet guarantees of mortgage-backed securities account for another $\$ 7$ trillion. Moreover, the risk associated with the government's liabilities is not idiosyncratic but varies systematically with macroeconomic conditions. For example, during the financial crisis, total off-balance sheet financial system backstops rose to more than $\$ 6$ trillion (Geithner [2014]). And, the U.S. debt-to-GDP ratio rose from $38 \%$ to $72 \%$ between 2007 and 2013 due to falling tax revenue and increasing expenditures on government programs that automatically expand during recessions (McKay and Reis [2016]).

Given the magnitude of these exposures, the portfolio choices made by the government - the set of risks it chooses to bear and the way it manages those risks - are of great importance. A vast literature in public economics studies the costs and benefits of individual government programs such as unemployment insurance and social security (Baily [1978], Chetty [2006]). An equally vast literature studies optimal government financing policies that minimize costly distortions, holding fixed the set of programs the government undertakes (Ramsey [1927], Diamond and Mirrlees [1971], Mirrlees [1971], Barro [1979]). In this paper, we bridge the gap between these two literatures, emphasizing the ways that government financing frictions impact the set of projects the government should undertake. The result is a flexible framework for conducting cost-benefit analysis in a dynamic, stochastic environment, where the government faces financing frictions.

In our model, a benevolent government chooses the scale of a program - designed to correct a specific market failure - whose social benefits and fiscal costs vary randomly over time and across states of the world. Our setup departs from the frictionless benchmark, where the government is a veil for taxpayers, in two critical ways. First, we assume that government programs can generate social benefits that private actors cannot generate on their own. We think of these benefits as arising from a variety of microfoundations: the government has a number of unique technologies for addressing market failures. For instance, it may use price or quantity regulations to correct technological externalities (Weitzman [1974]) or pecuniary externalities in incomplete markets (Greenwald and Stiglitz [1986]), enforce contributions to address free-rider problems in the provision of public goods (Samuelson [1954]), or mandate participation to address marketunravelling issues (Rothschild and Stiglitz [1976]). Because we take a portfolio view of the government's problem, we model the net social benefits of individual programs in reduced form, 
abstracting from these diverse microfoundations. The second key departure from the frictionless benchmark is that we assume that taxation is distortionary and creates deadweight efficiency losses (Ramsey [1927], Diamond and Mirrlees [1971], Mirrlees [1971], Saez [2001]). As a result, each dollar of tax revenue the government raises costs society more than a dollar in pre-tax resources, an additional cost that is common across all programs in the government's portfolio.

These two key frictions drive a rich set of intuitions, giving government cost-benefit analysis the flavor of a classic portfolio choice problem (Markowitz [1952], Tobin [1958], Sharpe [1964], Linter [1965]). A first key insight is that programs cannot be judged in isolation. In particular, the government has two risk management motives, which depend on the other programs in the government's portfolio. First, the fact that taxation is distortionary gives rise to a "fiscal risk management" motive: programs requiring large government outlays in states of the world where other government spending is elevated are unattractive. The distortionary costs of taxation push towards fiscal conservatism, effectively making the government more risk averse than the taxpayers it represents and raising the hurdle that needs to be cleared before the government undertakes a candidate program.

Second, there is a "social risk management" motive: when households are risk averse, programs that generate large net benefits in recessions, when household marginal utility is high, are attractive. An important subtlety that arises here is that the government cannot take household marginal utility as given: by operating large programs, the government affects aggregate consumption and thus household marginal utility. We use the model to provide a taxonomy of government programs that groups them based on their social and fiscal risk characteristics. This taxonomy provides a simple way to categorize any government program and to assess how considerations of social and fiscal risk should impact program scale.

A second key insight to emerge from the model is that the government's need to manage fiscal risk often limits its capacity for managing social risk. Indeed, we show the social and fiscal risk management motives typically pull in opposite directions as we vary the parameters of the economy or the program under consideration. For example, an increase in the volatility of exogenous private income makes deposit insurance more attractive from a social risk management standpoint: the value of preventing bank runs in bad times increases as marginal utility becomes more volatile. However, an increase in the volatility of private income also raises the volatility of tax rates, increasing fiscal risk. This reduces the attractiveness of an expansive deposit insurance regime. Since social risk and fiscal risk management considerations pull in opposite directions, the overall effect of an increase in volatility of private income is ambiguous in our model.

We illustrate this idea by fully solving a numerical example with a single government program: deposit insurance. In the example, deposit insurance is a social hedge, albeit one that 
is fiscally risky: we assume it generates large social benefits, raising output during recessions by preventing bank runs. However, deposit insurance also involves potentially large government outlays in the event of a severe recession. The example highlights how the government's two risk management motives come into conflict. Because deposit insurance involves large government outlays and hence greater tax distortions in bad times, it creates additional fiscal risk. This reduces the government's desire to use deposit insurance to manage social risk, particularly when tax distortions are large or when the pre-existing fiscal burden is high.

Finally, we extend our framework to allow the government to simultaneously choose the scales of multiple programs, making portfolio intuitions even more explicit. We consider an example in which the government chooses between two programs for promoting financial stability. We assume that regulation limiting bank risk taking ex ante is a "fiscally safe" way to promote financial stability because the associated expenditures vary little across states of the world. By contrast, deposit insurance may also promote financial stability, but is "fiscally risky" because the associated outlays vary significantly and may surge in a severe recession. Since deposit insurance entails costly increases in taxes, the attractiveness of deposit insurance versus regulations depends on the government's other fiscal commitments. For instance, if the government is also committed to a strong social safety net, which already requires large outlays in recessions, then deposit insurance will become less attractive relative to ex ante regulations. When the fiscal burden is high, it may be optimal to eschew deposit insurance and rely on regulation. These conclusions correspond to the classic portfolio choice intuition that an investor facing a higher level of "background risk" should choose a more conservative financial portfolio (Merton [1973], Campbell and Viceira [2002]). We also show that when the distortionary costs of taxation rise, the optimal quantity of fiscally risky deposit insurance falls. This corresponds to the precept that the optimal portfolio allocation to risky assets falls as risk aversion rises.

Work in public finance typically considers individual government interventions in isolation, studying the optimal provision of a single public good when the government must finance its expenditures using distortionary taxes. One strand of this literature studies a static, deterministic setting and concludes that program scale should equate marginal benefits with marginal costs, accounting for marginal tax distortions. ${ }^{1}$ A second strand studies project selection with stochastic payoffs that are only subject to idiosyncratic risk. ${ }^{2}$ Our model generalizes these classic public

\footnotetext{
${ }^{1}$ See, e.g., Pigou (1947), Samuelson (1954), Mirrless (1971), Stiglitz and Dasgupta (1971), Atkinson and Stern (1974), Ballard and Fullerton (1992). This work is recently surveyed in Kreiner and Verdelin (2012).

${ }^{2}$ Arrow and Lind (1970) argued that if the marginal net benefits of a program are only subject to idiosyncratic risk, those net benefits should be discounted at the riskless rate. Baumol (1968) pointed out that this result is not unique to the government: well-diversified private agents should also apply a riskless discount rate to projects that are only exposed to idiosyncratic risk.
} 
finance results to a multi-period, stochastic setting with general project costs and benefits. This allows us to study how risk, both social and fiscal, impacts optimal program scale. In particular, a program's social benefits and its fiscal costs, including costs of tax distortions, must be riskadjusted. These risk adjustments depend on the composition of the overall government portfolio, and can be large, particularly when the government's debt burden is high. The literatures on optimal taxation and government debt management recognize that government expenditures are stochastic and concludes that the government should smooth taxes over time when there are convex distortionary costs of taxation (Barro [1979]). ${ }^{3}$ However, this work typically treats the government as an exogenously given collection of programs. By contrast, our approach shows that the countercyclicality of government expenditures has important implications for the set of programs that should be undertaken by the government.

Our model also reveals strong parallels between government cost-benefit analysis and modern theories of corporate investment. In our setting, the distortionary costs of taxation play a similar role to the one that costly external finance plays in a corporate setting. Specifically, distortionary costs of taxation can lead the government to behave as though it is more risk-averse than the taxpayers it represents, just like financing frictions can lead firms to behave as though they are more risk-averse than shareholders. In a corporate finance setting, hedging and risk management activities can enhance firm value if external financing is costly (Froot, Scharfstein, and Stein [1993]), just as smoothing tax rates and debt management can create value for taxpayers when taxation is distortionary (Barro [1979]). By the same logic, financing frictions have implications for the optimal scale and composition of government projects in our setting, much as they do for firm investment (Fazzari, Hubbard, and Petersen [1988], Kaplan and Zingales [1997], Bolton, Chen, and Wang [2011 and 2013]).

The plan for the paper is as follows. Section 2 uses a simplified version of the model to show why social risk and fiscal risk considerations often pull in opposite directions. In Section 3, we develop the general model, and in Section 4 we characterize the optimal scale of a single government program. In Section 5, we explore several special cases of the general model that help clarify the key drivers of social and fiscal risk. Section 6 presents applications of our framework to financial stability programs. Section 7 concludes.

\footnotetext{
${ }^{3}$ In addition, our model embeds the core intuitions present in the state-contingent debt management problem studied in Bohn (1990), Aiyagari et al (2002), and Bhandari et al (2016), where the government issues risky securities to minimize tax distortions, as we discuss in the Internet Appendix.
} 


\section{The basic idea}

In this section, we use a simplified version of the model to present the two key insights of the paper: (i) social risk and fiscal risk affect the attractiveness of a program and (ii) these considerations almost always pull in opposite directions. We abstract from the complexities of the full portfolio optimization that we highlight in the general model.

There are two periods $t=0,1$. At time 0 a benevolent government decides whether or not to undertake a small project that will have a negligible effect on both aggregate household consumption and on the government budget. The project will require a random fiscal outlay of $X_{1}$ at time 1 with $E\left[X_{1}\right]>0$. These outlays will generate a random time 1 social payoff of $W_{1}$ where we assume the expected net benefits of the program are zero for starkness: $E\left[W_{1}-X_{1}\right]=0$. The government should undertake this project if its social net present value (NPV) is positive. The question is how to compute this social NPV.

The most naive calculation would be to say the social NPV of this project is

$$
N P V_{\text {naive }} \equiv R_{f}^{-1} E\left[W_{1}-X_{1}\right]
$$

where $R_{f}=1+r_{f}>1$ is the gross riskfree rate. Since we have assumed that $E\left[W_{1}-X_{1}\right]=0$, we have $N P V_{\text {naive }}=0$ by construction. Thus, using this naive rule, the government would be indifferent between undertaking the project and not.

Our model shows how to adjust this naive NPV calculation to incorporate both social risk and fiscal risk considerations. First, the naive calculation ignores social risk considerations by using a riskless rate to discount net benefits that may vary systematically with the state of the macroeconomy. Letting $M_{1}$ denote the stochastic discount factor that values payoffs in different states of the world at time 1 , the risk-adjusted NPV is

$$
N P V_{\text {risk }} \equiv E\left[M_{1}\left(W_{1}-X_{1}\right)\right]=N P V_{\text {naive }}+\operatorname{Cov}\left[M_{1}, W_{1}-X_{1}\right]
$$

where we have used the fact that $E\left[M_{1}\right]=R_{f}^{-1}$. If we assume that $\operatorname{Cov}\left[M_{1}, W_{1}-X_{1}\right]>0$, as would be the case for a program that generates large net benefits in recessionary states at time 1 , then we have $N P V_{\text {risk }}>N P V_{\text {naive }}=0$, which reflects the government's social risk management motive. Thus, a government that only adjusted for social risk would always undertake the project. This kind of risk adjustment is crucial for many government programs like automatic stabilizers and financial stability programs because they are designed to generate countercyclical benefits.

Second, the naive calculation ignores marginal financing costs associated with the program's outlays. In particular, financing the fiscal outlays associated with the program is costly because 
taxation is distortionary, and the NPV calculation should take these costs into account. We first adjust the net benefits to account for these marginal fiscal costs, but continue to naively use a riskfree discount rate. The adjusted net benefit is $W_{1}-X_{1}\left(1+h_{1}^{\prime}\right)$ where $h_{1}^{\prime}>0$ is the marginal distortionary costs of raising government revenue at $t=1$. Importantly, we assume that $h_{1}^{\prime}$ is unknown at time 0 and varies across states at time 1 due to stochastic variation in other government expenditures. Then the tax-adjusted social NPV is

$$
N P V_{\text {tax }} \equiv R_{f}^{-1} E\left[W_{1}-X_{1}\left(1+h_{1}^{\prime}\right)\right]=N P V_{\text {naive }}-R_{f}^{-1} E\left[h_{1}^{\prime}\right] E\left[X_{1}\right]-R_{f}^{-1} \operatorname{Cov}\left[h_{1}^{\prime}, X_{1}\right]
$$

The first adjustment to $N P V_{\text {naive }}$ reflects the expected fiscal costs of the program. The second adjustment reflects what we call fiscal risk management: programs that require high outlays in states where the marginal fiscal costs are high are less desirable. Assuming that $\operatorname{Cov}\left[h_{1}^{\prime}, X_{1}\right]>0$, we have $N P V_{t a x}<N P V_{\text {naive }}=0$. Thus, a government that only adjusted for fiscal risk would never take on the project.

Finally, we compute a social NPV that reflects both social and fiscal risk considerations:

$$
N P V_{\text {tax }+ \text { risk }} \equiv E\left[M_{1}\left(W_{1}-X_{1}\left(1+h_{1}^{\prime}\right)\right)\right]=N P V_{t a x}+\operatorname{Cov}\left[M_{1}, W_{1}-X_{1}\left(1+h_{1}^{\prime}\right)\right]
$$

If we assume that $\operatorname{Cov}\left[M_{1}, W_{1}-X_{1}\left(1+h_{1}^{\prime}\right)\right]>0$, then we have $N P V_{t a x+r i s k}>N P V_{t a x}$. In this example, the fiscal risk adjustment and the social risk adjustment pull in opposite directions, and the net effect relative to $N P V_{\text {naive }}=0$ is ambiguous. Below, we argue that this tension regularly arises in government cost-benefit analysis: the need to manage fiscal risk generally limits the government's ability to manage social risk.

The full model we develop below captures these basic intuitions, characterizing the conditions when the two risk management motives conflict. Crucially, our full model also accounts for the fact that $M_{1}$ and $h_{1}^{\prime}$ change when the government makes large investments in programs that affect aggregate consumption and the overall government budget. By way of analogy to portfolio choice, this parallels the idea that mean-variance analysis is necessary when making large changes to a portfolio. One cannot simply use a fixed hurdle rate based on the "portfolio improvement rule," as we implicitly did above, which is only appropriate when evaluating small marginal changes to an existing portfolio (Perold [2004] and Berk and DeMarzo [2017]). 


\section{Model}

In this section, we consider the problem of choosing the optimal scale of a single government program, holding fixed the rest of the portfolio. In Section 6, we show that the model easily extends to the problem of choosing the optimal portfolio of government programs.

\subsection{Setup}

We consider a two-period model with dates $t=0$ and 1 . At time 0 , a benevolent government chooses the scale of a program, denoted $q$, and initial borrowing $D_{0}$ to maximize the lifetime expected utility of a representative household. Since we want to develop a general model that can be applied to many programs, we model the program's social benefits and required fiscal outlays in reduced form. ${ }^{4}$ Specifically, if the government chooses scale $q$, the program generates a social payoff $W_{t}(q)$ at time $t$, where $W_{t}(0)=0, W_{t}^{\prime}>0$, and $W_{t}^{\prime \prime} \leq 0$. $W_{0}(q)$ is known at $t=0$ when the government must choose $q$ and $D_{0}$. At $t=0, W_{1}(q)$ is stochastic, varying across states of the world which differ in terms of output and government outlays on other programs. For instance, deposit insurance may create financial stability benefits that raise output in bad states at $t=1$, implying $W_{1}(q)>0$ in bad time 1 states. The program requires government outlays of $X_{t}(q)$ at time $t$, where $X_{t}(0)=0, X_{t}^{\prime}>0$, and $X_{t}^{\prime \prime} \geq 0$. At $t=0, X_{0}(q)$ is known and $X_{1}(q)$ is stochastic.

The rest of the government's portfolio of programs requires outlays of $G_{t}$. For now, we take these other expenditures as exogenously given when choosing the scale $q$ of the specific program under consideration. At $t=0, G_{0}$ is known and $G_{1}$ is stochastic.

We assume that the government enters time 0 having previously accumulated debt $\bar{D}$ that must be repaid at time 0 . Comparative statics with respect to $\bar{D}$ will allow us to understand how the optimal government portfolio varies with the government's existing debt burden. At time 0 , the government issues 1-period, default-free bonds in quantity $D_{0}$ that mature at time 1. Letting $R_{f}=1+r_{f}>1$ denote the gross riskless interest rate between times 0 and 1 , the government's budget constraints at time 0 and time 1 are

$$
T_{0}+D_{0}=G_{0}+X_{0}(q)+\bar{D} \text { and } T_{1}=G_{1}+X_{1}(q)+R_{f} D_{0} .
$$

\footnotetext{
${ }^{4}$ The net social benefits generated by different government programs have a diverse set of underlying microfoundations. For instance, some programs generate net social benefits because they correct technological externalities or pecuniary externalities in incomplete markets, others address free-rider problems in the provision of public goods, others mandate participation to address market-unravelling issues, etc. In Section 5, we develop an example that microfounds the benefits and costs of a specific program (deposit insurance).
} 
Here $T_{t}$ is tax revenue at time $t, X_{t}(q)$ is the endogenous level of expenditures associated with the program under consideration, and $G_{t}$ is other exogenous government expenditures.

A key feature of our setup is that taxation is distortionary. Specifically, we assume the government raises revenue through an income tax that distorts labor supply choices, creating deadweight costs that reduce output and household consumption. The government takes these distortionary costs into account when optimally choosing program scale.

Since taxes are distortionary, Ricardian equivalence fails - i.e., the way the government finances its expenditures using debt and taxes has implications for household utility. Thus, it is natural to allow the government to borrow at time 0 when choosing program scale. ${ }^{5}$ Indeed, the ability to borrow in order to smooth taxes - and the resulting deadweight losses - over time plays a central role in many theories of optimal fiscal policy (Barro (1979)). Specifically, when choosing program scale $q$, the government in our model knows it can borrow to optimally smooth the resulting expected tax burden over time, which feeds back into its optimal choice of $q$.

Here we provide a brief microfoundation for the distortionary costs of taxation. We do so because this common fiscal friction applies to all government programs, tying them together to give fiscal risk its portfolio flavor. Furthermore, our microfoundation helps link our results to the existing public economics literature. Specifically, we assume that households choose their labor supply $\ell_{t}$ in period $t$ to maximize their period $t$ payoff:

$$
C_{t}\left(\ell_{t}\right)=Y_{t}[\overbrace{\ell_{t}\left(1-\tau_{t}\right)}^{\text {After-tax income }}-\overbrace{\left(\left(\ell_{t}-1+\eta\right)^{2}-\eta^{2}\right) /(2 \eta)}^{\text {Disutility from labor }}]+W_{t}(q)+(\text { Net trade gov't bonds })_{t},
$$

which we refer to as consumption. Here $Y_{t}$ is the exogenous level of productivity at time $t$, which we refer to as the "tax base," $\tau_{t}$ is the proportional income tax levied by the government at time $t$, and $\eta \geq 0$ governs the elasticity of labor with respect to $\tau_{t}$. We assume that $Y_{1}$ is stochastic and takes on different values in different states at time 1 . Thus, different states at $t=1$ correspond to different realizations of the tuple $\left(Y_{1}, G_{1}, X_{1}(q), W_{1}(q)\right)$. The period $t$ payoff, $C_{t}$, in Eq. (6) takes a quasilinear form with after-tax income serving as numeraire.

\footnotetext{
${ }^{5}$ By way of analogy, when studying optimal firm investment in a setting where it is costly to raise external equity but not external debt-i.e., where the Modigliani-Miller theorem fails, it is natural to allow firms to jointly choose both their investment and their debt versus equity mix (Stein [1996]). In the Internet Appendix, we solve the model when the government is not allowed to borrow at $t=0$. If we constrain the government to choose $D_{0}=0$, optimal program scale is still be pinned down by Equation (22) below. However, imposing $D_{0}=0$ impacts the optimal scale $q$ because the inability to smooth the expected tax burden over time impacts the expected fiscal costs of the program. Indeed, consistent with Samuelson's (1947) Le Chatelier Principle, which states that comparative statics are smaller in magnitude when an optimizing agent is not permitted to adjust related control variables, we show that the government adjusts program scale less elastically in response to changes in the discounted net benefits when it is not simulatenously allowed to adjust its debt issuance.
} 
Thus, $Y_{t}\left(\left(\ell_{t}-1+\eta\right)^{2}-\eta^{2}\right) /(2 \eta)$ captures disutility from supplying $\ell_{t}$ units of labor and $W_{t}(q)$ is the additional payoff households derive when the government chooses program scale $q$. This quasilinear specification is similar to the one in Atkinson (1990) and Diamond (1998).

By Eq. (6), the optimal labor supply when households face an income tax rate of $\tau_{t}$ is $\ell_{t}^{*}=1-\eta \tau_{t}$, which compares to the first-best labor supply of $\ell_{t}^{* *}=1$ under lump-sum taxation. Thus, an income tax at rate $\tau_{t}$ generates total tax revenues of $T_{t}=\tau_{t} \ell_{t}^{*} Y_{t} \leq \tau_{t} Y_{t}$, which implicitly links the level of tax revenue $T_{t}$ to the tax rate $\tau_{t}$. Deadweight loss is created because income taxation disincentivizes labor so $T_{t} \leq \tau_{t} Y_{t}$. The tax rate that raises revenue $T_{t}$ while minimizing deadweight loss is given by

$$
\tau_{t}=\frac{1-\sqrt{1-4 \eta T_{t} / Y_{t}}}{2 \eta} .
$$

The deadweight loss of taxation is

$$
C_{t}\left(\ell_{t}^{* *}\right)-C_{t}\left(\ell_{t}^{*}\right)-T_{t}=Y_{t} \frac{\eta}{2} \tau_{t}^{2},
$$

as in Harberger (1962). Naturally, the deadweight loss is greater when tax rates are higher or when the elasticity of labor supply with respect to tax rates, $\eta$, is larger. When $\eta=0$, income taxation generates no deadweight losses.

When $\eta>0$, each dollar of tax revenue costs society more than a dollar in pre-tax resources. The total cost of public funds (Browning [1976]) is equal to the amount of tax revenue raised plus the deadweight loss: $T_{t}+Y_{t}(\eta / 2) \tau_{t}^{2}$. As a result, the marginal cost of public funds is

$$
\frac{\partial}{\partial T_{t}}\left(T_{t}+Y_{t} \frac{\eta}{2} \tau_{t}^{2}\right)=1+\frac{\eta \tau_{t}}{1-2 \eta \tau_{t}} \geq 1 .^{6}
$$

In what follows, we use the notation

$$
h^{\prime}\left(\tau_{t}\right) \equiv \frac{\eta \tau_{t}}{1-2 \eta \tau_{t}} \geq 0
$$

to denote the extent to which the marginal cost of public funds exceeds one. In other words, $h^{\prime}\left(\tau_{t}\right)$ is the marginal deadweight cost of raising an additional dollar of revenue via distortionary taxation. Naturally, we have $h^{\prime \prime}>0$ : the marginal cost of public funds is increasing in the tax rate because higher rates imply greater labor supply distortions. This gives the government motive to smooth tax rates over time as in Barro (1979). There is a large public finance literature seeking

\footnotetext{
${ }^{6}$ The marginal cost of public funds exceeds one if the elasticity of labor supply with respect to taxes is negative. In a more general model, the sign of this elasticity is ambiguous. It is the sum of a negative substitution effect and a positive wealth effect: higher taxes make households poorer and thus motivate them to work more. Given our quasilinear specification of the per-period payoff, only the substitution effect is present.
} 
to estimate the marginal deadweight cost of public funds, $h^{\prime}\left(\tau_{t}\right)$, with estimates ranging from 0.05 to 0.2 in the U.S. (Browning (1976), Mayshar (1990), McClelland and Mok (2012)).

The lifetime utility of the representative household is

$$
U=u\left(C_{0}\right)+\beta E\left[u\left(C_{1}\right)\right]
$$

where $0<\beta \leq 1, u^{\prime}>0$, and $u^{\prime \prime} \leq 0$. When $u^{\prime \prime}=0$, marginal utility is constant and households are risk neutral; when $u^{\prime \prime}<0$, households are risk averse. Imposing market clearing for government bonds and using the fact that the government's budget constraint implies (Net trade gov't bonds) ${ }_{t}=T_{t}-X_{t}(q)-G_{t}$, the Appendix shows that household consumption is

$$
C_{t}=Y_{t}\left(1-(\eta / 2) \tau_{t}^{2}\right)+W_{t}(q)-X_{t}(q)-G_{t}
$$

Eqs. (11) and (12) show that the deadweight costs of distortionary taxation given in Eq. (8) reduce household consumption and, thus, household utility.

\subsection{Discussion of model setup}

Several features of the model setup deserve discussion. First, we adopt a representative agent perspective. However, if market failures create scope for government policies to generate Pareto improvements, a representative agent may fail to exist (Huang and Litzenberger [1988], Duffie [2001]). In cases where no representative agent exists, our framework should be viewed as a short-hand for maximization of a more complicated social welfare function.

Second, the source of fiscal frictions in our model is incentive distortions stemming from proportional taxation (Ramsey [1927], Diamond and Mirrlees [1971], Mirrlees [1971], Saez [2001]). Taken literally, this means that, with lump-sum taxation, there would be no fiscal frictions. While we refer to distortions $h^{\prime}(\tau)$ as "tax distortions," they are best seen as a short-hand for a host of frictional costs that the government may face. For instance, there may be real costs associated with the risk of sovereign default (Borensztein and Panizza [2009]) or with the high rates of inflation that can be triggered by large government debt burdens, as in Leeper's (1991) fiscal theory of the price level. Such costs can be particularly relevant when thinking about financial stability programs, as argued by the recent literature on the sovereign-bank nexus (e.g., Acharya, Drechsler, and Schnabl [2014], Brunnermeier et al [2016]).

Third, we focus on a two-period setting. It is easy to extend the analysis to an infinite-horizon setting so the notion of risk acquires a more dynamic flavor. The only take-away from this extension is that persistent shocks play a more important role than transient shocks in determining 
social and fiscal risk. Specifically, in the face of transitory fiscal shocks, the government can borrow to smooth tax rates, reducing the deadweight losses associated with high and variable tax rates. By contrast, persistent fiscal shocks lead to larger changes in taxes and, thus, greater deadweight losses. As a result, optimal program scale is smaller when shocks to either $G_{t}$ or $X_{t}$ are more persistent. Relatedly, we assume that the government makes a one-shot choice about program scale and can commit to this scale in the future. Thus, the model is best seen as applying to non-discretionary programs where, for reasons of political economy, efficiency, or fairness, program scale is stable over time. However, we have also considered a variant of the model where the government is free to dynamically adjust program scale over time.

Fourth, the setup largely abstracts from the fact that government programs may distort the behavior of private agents. For instance, government insurance programs may create moral hazard problems (Baily [1978], Allen et al [2015]). Private agents' responses to a given program may impact $W_{t}(q)$ and $X_{t}(q)$ and these responses should be folded into these reduced-form benefit and outlay functions.

Fifth, while program scale impacts household utility, it does not impact the tax base in our model. This is an appropriate assumption if the government raises revenue to produce a classic public good such as national security, which cannot be taxed. However, in other cases, the social benefits, $W_{t}(q)$, may add to the tax base. For a financial stability program may help prevent collapses in private output due to bank runs. In the Internet Appendix, we show how to modify the analysis if $W_{t}(q)$ adds to the tax base. In this case, the normal tension between fiscal and social risk management is partially alleviated. Specifically, programs that add to the the tax base are valuable because they help keep tax rates and the associated deadweight losses low. ${ }^{7}$

\section{Optimal government policy}

\subsection{The government's problem}

The government's problem is to choose program scale $q$ and borrowing $D_{0}$ at time 0 , which together determine the path of taxes, to maximize the lifetime utility of the representative household. The government takes $\bar{D},\left(Y_{0}, G_{0}, W_{0}(q), X_{0}(q)\right)$, and the distribution of the random

\footnotetext{
${ }^{7}$ In this case, the Internet Appendix shows that in Eq. (22) - the optimality condition for $q-W_{t}^{\prime}(q)$ should be replaced with $W_{t}^{\prime}(q)\left(1+\frac{\tau_{t}}{2} h^{\prime}\left(\tau_{t}\right)\right) \geq W_{t}^{\prime}(q)$. Otherwise, the analysis is similar.
} 
variables $\left(Y_{1}, G_{1}, W_{1}(q), X_{1}(q)\right)$ as given. Formally, the government solves

$$
\max _{D_{0}, q}\left\{u\left(Y_{0}\left(1-\frac{\eta}{2} \tau_{0}^{2}\right)+W_{0}(q)-X_{0}(q)-G_{0}\right)+\beta E\left[u\left(Y_{1}\left(1-\frac{\eta}{2} \tau_{1}^{2}\right)+W_{1}(q)-X_{1}(q)-G_{1}\right)\right]\right\} .
$$

In choosing $D_{0}$ and $q$, the government recognizes that tax rates $\tau_{0}$ and $\tau_{1}$ depend on its choices of $D_{0}$ and $q$ and are given by

$$
\tau_{0}=\frac{1-\sqrt{1-4 \eta \frac{G_{0}+X_{0}(q)+\bar{D}-D_{0}}{Y_{0}}}}{2 \eta} \text { and } \tau_{1}=\frac{1-\sqrt{1-4 \eta \frac{G_{1}+X_{1}(q)+R_{f} D_{0}}{Y_{1}}}}{2 \eta} \text {. }
$$

Equation (14) follows from equation (7) by substituting in tax revenue $T_{t}$ from equation (5).

Somewhat more subtly, when households are risk averse $\left(u^{\prime \prime}<0\right)$ and when taxes are distortionary $(\eta>0)$, the government must recognize that it cannot take the riskless interest rate as exogenously given when choosing $q$ and $D_{0} \cdot{ }^{8}$ Household's Euler equation for holding riskless bonds is given by

$$
u^{\prime}\left(C_{0}\right)=R_{f} \beta E\left[u^{\prime}\left(C_{1}\right)\right],
$$

which implicitly defines $R_{f}$ in terms of $q$ and $D_{0}$ once we substitute in for consumption:

$$
u^{\prime}\left(Y_{0}\left(1-\frac{\eta}{2} \tau_{0}^{2}\right)+W_{0}(q)-X_{0}(q)-G_{0}\right)=R_{f} \beta E\left[u^{\prime}\left(Y_{1}\left(1-\frac{\eta}{2} \tau_{1}^{2}\right)+W_{1}(q)-X_{1}(q)-G_{1}\right)\right]
$$

Since the government's choices of $q$ and $D_{0}$ affect aggregate consumption at both time 0 and 1 (the choice of $D_{0}$ affects consumption indirectly via taxes; the choice of $q$ affects consumption both directly and indirectly via taxes), these choices also impact the riskless rate.

In summary, the government solves the maximization problem in Eq. (13) where it recognizes that tax rates and the riskfree rate are implicitly defined by Eqs. (14) and (16).

\subsection{Model solution}

We now characterize optimal government policy. We first explain how government policies impact the riskless interest rate $R_{f}$. We then turn to the optimality conditions for government borrowing $D_{0}$ and program scale $q$.

\footnotetext{
${ }^{8}$ We are grateful to George Constantinides for pointing this out. We treat this complication for the sake of completeness. However, it does not drive any of the key intuitions that emerge from our model.
} 


\subsubsection{The impact of government policy on the riskfree rate}

As discussed above, program scale $q$ impacts the riskless rate because it impacts aggregate consumption. We have

$$
\frac{\partial R_{f}}{\partial q}=-\frac{R_{f} \beta E\left[u^{\prime \prime}\left(C_{1}\right)\left(W_{1}^{\prime}(q)-X_{1}^{\prime}(q)\left(1+h^{\prime}\left(\tau_{1}\right)\right)\right)\right]-u^{\prime \prime}\left(C_{0}\right)\left(W_{0}^{\prime}(q)-X_{0}^{\prime}(q)\left(1+h^{\prime}\left(\tau_{0}\right)\right)\right)}{\beta E\left[u^{\prime}\left(C_{1}\right)-R_{f} D_{0} u^{\prime \prime}\left(C_{1}\right) h^{\prime}\left(\tau_{1}\right)\right]} .
$$

The sign of $\partial R_{f} / \partial q$ is ambiguous and depends on the nature of the program under consideration. For example, if a program is expected to raise $C_{1}$ relative to $C_{0}$, households will want to borrow more at time 0 to smooth consumption, causing the interest rate to rise.

Similarly, borrowing $D_{0}$ affects the riskless rate. Specifically, we have

$$
\frac{\partial R_{f}}{\partial D_{0}}=\frac{R_{f}^{2} \beta E\left[u^{\prime \prime}\left(C_{1}\right) h^{\prime}\left(\tau_{1}\right)\right]+u^{\prime \prime}\left(C_{0}\right) h^{\prime}\left(\tau_{0}\right)}{\beta E\left[u^{\prime}\left(C_{1}\right)-R_{f} D_{0} u^{\prime \prime}\left(C_{1}\right) h^{\prime}\left(\tau_{1}\right)\right]} \leq 0 .
$$

When taxes are distortionary $\left(h^{\prime}>0\right)$, borrowing more today lowers current taxes and tax distortions, thereby raising current consumption. It also raises future taxes and tax distortions, lowering expected future consumption. When households are risk averse $\left(u^{\prime \prime}<0\right)$, this means that current marginal utility $\left(u^{\prime}\left(C_{0}\right)\right)$ falls and future marginal utility $\left(u^{\prime}\left(C_{1}\right)\right)$ rises in expectation. As a result, households want to save more at time 0 , so $R_{f}$ must fall.

\subsubsection{Optimal government borrowing}

With these two comparative statics in hand, we now turn to optimal borrowing at time 0 . The first-order condition for $D_{0}$ can be written as

$$
u^{\prime}\left(C_{0}\right) h^{\prime}\left(\tau_{0}\right)=\left(R_{f}+D_{0} \frac{\partial R_{f}}{\partial D_{0}}\right) \beta E\left[u^{\prime}\left(C_{1}\right) h^{\prime}\left(\tau_{1}\right)\right] .
$$

As in Barro (1979), the government chooses its time 0 borrowing $D_{0}$ to smooth the expected deadweight costs of taxation over time. Since these deadweight costs are a convex function of the tax rate, the government would like to smooth tax rates in expectation over time, even if government outlays and the tax base are not expected to be constant.

To derive this condition, suppose the government issues a bit more debt at time 0 and reduces tax revenue by the same amount. This deviation reduces tax distortions by $h^{\prime}\left(\tau_{0}\right)$ at time 0 , which raises utility at time 0 by $u^{\prime}\left(C_{0}\right) h^{\prime}\left(\tau_{0}\right)$. Since this deviation raises taxes by $\left(R_{f}+D_{0} \frac{\partial R_{f}}{\partial D_{0}}\right)$

at time 1 , it raises future tax distortions by $\left(R_{f}+D_{0} \frac{\partial R_{f}}{\partial D_{0}}\right) h^{\prime}\left(\tau_{1}\right)$ at time 1 . This lowers discounted expected utility by $\left(R_{f}+D_{0} \frac{\partial R_{f}}{\partial D_{0}}\right) \beta E\left[u^{\prime}\left(C_{1}\right) h^{\prime}\left(\tau_{1}\right)\right]$. Eq. (19) says that, at an optimum, such a 
deviation must have zero effect on expected lifetime utility.

When there are no fiscal frictions $\left(h^{\prime}=0\right)$, only the scale of the government program $(q)$ impacts household welfare. Ricardian equivalence holds, so the mix of debt and taxes used to finance expenditures is irrelevant, and $D_{0}$ is not pinned down (Barro [1974]).

\subsubsection{Optimal program scale}

We now turn to the optimal scale of the program. The first-order condition for $q$ is given by

$$
0=u^{\prime}\left(C_{0}\right)\left(\frac{\partial C_{0}}{\partial q}+\frac{\partial C_{0}}{\partial \tau_{0}} \frac{\partial \tau_{0}}{\partial q}\right)+\beta E\left[u^{\prime}\left(C_{1}\right)\left(\frac{\partial C_{1}}{\partial q}+\frac{\partial C_{1}}{\partial \tau_{1}} \frac{\partial \tau_{1}}{\partial q}\right)\right]
$$

We can write the effect of changing $q$ on household consumption at times 0 and 1 as:

$$
\begin{aligned}
& \frac{\partial C_{0}}{\partial q}+\frac{\partial C_{0}}{\partial \tau_{0}} \frac{\partial \tau_{0}}{\partial q}=W_{0}^{\prime}(q)-X_{0}^{\prime}(q)-h^{\prime}\left(\tau_{0}\right) X_{0}^{\prime}(q) \\
& \frac{\partial C_{1}}{\partial q}+\frac{\partial C_{1}}{\partial \tau_{1}} \frac{\partial \tau_{1}}{\partial q}=W_{1}^{\prime}(q)-X_{1}^{\prime}(q)-h^{\prime}\left(\tau_{1}\right) X_{1}^{\prime}(q)-h^{\prime}\left(\tau_{1}\right) D_{0} \frac{\partial R_{f}}{\partial q}
\end{aligned}
$$

Increasing program scale directly alters time $t$ consumption by $W_{t}^{\prime}(q)-X_{t}^{\prime}(q)$ and increases the deadweight loss from distortionary taxation by $h^{\prime}\left(\tau_{t}\right) X_{t}^{\prime}(q)$. There is an additional term at time 1 , namely $h^{\prime}\left(\tau_{1}\right) D_{0} \frac{\partial R_{f}}{\partial q}$, reflecting the fact that the choice of $q$ affects the interest rate $R_{f}$ and thus required tax revenue at time 1.

Thus, the optimal amount of government activity satisfies

$$
\begin{aligned}
0= & u^{\prime}\left(C_{0}\right)\left(W_{0}^{\prime}(q)-X_{0}^{\prime}(q)-h^{\prime}\left(\tau_{0}\right) X_{0}^{\prime}(q)\right) \\
& +\beta E\left[u^{\prime}\left(C_{1}\right)\left(W_{1}^{\prime}(q)-X_{1}^{\prime}(q)-h^{\prime}\left(\tau_{1}\right) X_{1}^{\prime}(q)-h^{\prime}\left(\tau_{1}\right) D_{0} \frac{\partial R_{f}}{\partial q}\right)\right]
\end{aligned}
$$

Proposition 1 An optimum is a pair $\left(D_{0}^{*}, q^{*}\right)$ such that $D_{0}^{*}$ and $q^{*}$ satisfy Eqs. (19) and (22), and where $\tau_{0}, \tau_{1}$, and $R_{f}$ are implicitly defined by Eqs. (14) and (16).

Proof. All proofs are given in the Appendix.

\subsection{A decomposition of the condition for optimal program scale}

To interpret the first-order condition in Eq. (22), let

$$
M_{1}=\beta \frac{u^{\prime}\left(Y_{1}\left(1-\frac{\eta}{2} \tau_{1}^{2}\right)+W_{1}(q)-X_{1}(q)-G_{1}\right)}{u^{\prime}\left(Y_{0}\left(1-\frac{\eta}{2} \tau_{0}^{2}\right)+W_{0}(q)-X_{0}(q)-G_{0}\right)}
$$


denote the representative household's stochastic discount factor, which follows by substituting $C_{t}$ in Eq. (12) into the standard definition of the stochastic discount factor $M_{1} \equiv \beta u^{\prime}\left(C_{1}\right) / u^{\prime}\left(C_{0}\right)$ and noting that $R_{f}^{-1}=E\left[M_{1}\right]$ by Eq. (16). In the Appendix we show that the optimal scale of the government program satisfies

$$
\begin{aligned}
0= & \overbrace{\left(W_{0}^{\prime}(q)-X_{0}^{\prime}(q)\right)+R_{f}^{-1} E\left[W_{1}^{\prime}(q)-X_{1}^{\prime}(q)\right]}^{\text {Expected marginal net benefit }} \\
& -\overbrace{\left(h^{\prime}\left(\tau_{0}\right) X_{0}^{\prime}(q)+R_{f}^{-1} E\left[h^{\prime}\left(\tau_{1}\right)\right] E\left[X_{1}^{\prime}(q)+D_{0} \frac{\partial R_{f}}{\partial q}\right]\right)}^{\text {Expected fiscal cost }} \\
& +\underbrace{\operatorname{Cov}\left[M_{1}, W_{1}^{\prime}(q)-X_{1}^{\prime}(q)\right]}_{\text {Social risk management }}-\underbrace{R_{f}^{-1} \operatorname{Cov}\left[h^{\prime}\left(\tau_{1}\right), X_{1}^{\prime}(q)\right]}_{\text {Fiscal risk management }}-\underbrace{\operatorname{Cov}\left[M_{1}, h^{\prime}\left(\tau_{1}\right)\left(X_{1}^{\prime}(q)+D_{0} \frac{\partial R_{f}}{\partial q}\right)\right]}_{\text {Interaction between social and fiscal risk }} .
\end{aligned}
$$

Before interpreting the five terms in Eq. (24) we first note that certain terms disappear in different limiting cases. First, if there is no uncertainty about the state of the world at $t=1$, the third, fourth, and fifth terms are zero. ${ }^{9}$ Second, if households are risk neutral $\left(u^{\prime \prime}=0\right)$, then $M_{1}=R_{f}^{-1}$ is constant and the third and fifth terms are zero. Third, if there are no tax distortions $\left(h^{\prime}=0\right)$, the second, fourth, and fifth terms are zero.

We now interpret the five terms in Eq. (24) that impact the optimal scale of a government program. The first term in Eq. (24) is the expected marginal net benefit from the program, discounted at the riskfree rate. This term reflects the way that the outlays associated with explicit guarantee programs are accounted for in the U.S. federal budget. Specifically, under the Federal Credit Reform Act (FCRA) of 1990, the scored cost of a guarantee program equals the expected net present value of government outlays discounted at the riskfree rate. ${ }^{10}$

The second term in Eq. (24) captures the expected fiscal cost of the program. When taxes are distortionary $\left(h^{\prime}>0\right)$, this term makes programs less desirable if they raise average taxes, i.e., if $X_{0}^{\prime}(q)$ and $E\left[X_{1}^{\prime}(q)+D_{0} \partial R_{f} / \partial q\right]$ are large. Since $h^{\prime \prime}>0$, these expected fiscal costs are greater when the expected level of tax rates is higher. By contrast, if $h^{\prime}=0$, the model collapses to the Ricardian case where the government is a veil for taxpayers. Crucially, $h^{\prime}$ depends on the scale of the program $q$ via tax rates (see Eq. (10) and (14)). This effect can be ignored when considering small programs within the government's portfolio, but not large programs.

The third term in Eq. (24) reflects the government's social risk management motive. When households are risk averse $\left(u^{\prime \prime}<0\right)$, the government wants to undertake more of a program if

\footnotetext{
${ }^{9}$ This is the case considered in the public finance literature studying the provision of public goods when the government finances its expenditures using distortionary taxes. See Kreiner and Verdelin (2012) for a review.

${ }^{10}$ See Lucas (2012) for a summary of FCRA. Of course, there are numerous implicit guarantee programs that are not accounted for in the U.S. federal budget.
} 
its net benefits tend to accrue in bad time 1 states when household marginal utility is highi.e., if $\operatorname{Cov}\left[M_{1}, W_{1}^{\prime}(q)-X_{1}^{\prime}(q)\right]>0$. By contrast, there is no social risk management motive if households are risk neutral $\left(u^{\prime \prime}=0\right) .{ }^{11}$

Again, a critical point about this social risk management term is that the stochastic discount factor $M_{1}$ itself depends on the scale of the government program $q$ (see Eq. (23)). Government projects have the potential to alter aggregate consumption and therefore cannot be treated as "marginal," a point first noted by Dasgupta, Sen, and Marglin (1972), Little and Mirrlees (1974), and recently emphasized by Martin and Pindyck (2015). As above, this complication can be safely ignored for small programs, but not large programs. For instance, if government policies reduce the volatility of aggregate consumption and hence marginal utility, risk premia will be smaller than they would in the corresponding economy where $q=0$. Thus, the existence of government programs may alter household attitudes towards risky projects, including government programs. As discussed below, this also means that changes in the parameters governing a particular government program have both substitution and income effects, leading to ambiguous comparative statics.

The fourth term in Eq. (24) captures the government's fiscal risk management motive. When $h^{\prime}>0$, tax distortions lead the government to act as if it is more risk-averse than the taxpayers it represents. Specifically, this term makes government programs less desirable if they tend to require high outlays and, thus, tend to raise taxes in states of the world where tax rates are already elevated (i.e., if $\operatorname{Cov}\left[h^{\prime}\left(\tau_{1}\right), X_{1}^{\prime}(q)\right]$ is large). By contrast, if $h^{\prime}=0$, there is no fiscal risk management motive.

As we emphasize below, the social risk management motive captured by the third term in (24) and the fiscal risk management motive captured by the fourth term often conflict. Programs like deposit insurance and automatic stabilizers, which may have significant social risk management benefits, tend to involve government outlays and, hence, higher tax distortions in bad times, creating greater fiscal risk. Thus, when evaluating a large government program, the third and fourth terms in Eq. (24) will often pull in opposite directions.

The final term in Eq. (24), $\operatorname{Cov}\left[M_{1}, h^{\prime}\left(\tau_{1}\right)\left(X_{1}^{\prime}(q)+D_{0} \partial R_{f} / \partial q\right)\right]$, is the risk premium stemming from the cyclicality of taxes and reflects the interaction between the government's social and fiscal risk management motives. Specifically, if a program leads to increased taxes in bad times, tax distortions reduce private consumption precisely when it is most valuable, leading the

\footnotetext{
${ }^{11}$ In contrast to U.S. budgeting procedures, economists have frequently argued - see Lucas (2012) and the citations within - that the government should include a risk adjustment term $\operatorname{Cov}\left[M_{1}, X_{1}^{\prime}(q)\right]$ when assessing the budgetary cost of government programs. Of course, as Lucas (2012) notes, a proper cost-benefit analysis requires one to risk adjust both the social benefits and and the outlays associated with a program-i.e., one adds $\operatorname{Cov}\left[M_{1}, W_{1}^{\prime}(q)-X_{1}^{\prime}(q)\right]$, precisely as dictated by our framework.
} 
government to do less of the program than it otherwise might.

\subsection{A taxonomy of government programs}

Our key first-order condition (24) yields a natural taxonomy of government programs. The taxonomy has two dimensions: whether social risk considerations are relevant for the program (i.e., whether $\operatorname{Cov}\left[M_{1}, W_{1}^{\prime}(q)-X_{1}^{\prime}(q)\right] \neq 0$ ) and whether fiscal risk considerations are relevant (i.e., whether $\operatorname{Cov}\left[h^{\prime}\left(\tau_{1}\right), X_{1}^{\prime}(q)\right] \neq 0$ ). This taxonomy highlights the value of our general framework, and sheds light on how different programs fit into the government's portfolio.

To be clear, our goal in this section is not to argue that there is necessarily a strong economic rationale for individual programs. Instead, we simply use our framework to highlight whether considerations related to social risk or fiscal risk are likely to play an important role in a comprehensive analysis of each program.

\subsubsection{Neither social nor fiscal risk are important}

A first set of programs are those with neither social risk nor fiscal risk (i.e., $\operatorname{Cov}\left[M_{1}, W_{1}^{\prime}(q)-X_{1}^{\prime}(q)\right]=$ 0 and $\left.\operatorname{Cov}\left[h^{\prime}\left(\tau_{1}\right), X_{1}^{\prime}(q)\right]=0\right)$. In this case, only the first two terms in Eq. (24) will be important. Programs in this category arguably include government insurance protection for floods, terrorism, and crop failures, regulations for food and drug safety, and federal subsidies for basic research and education.

Turning first to insurance for floods, terrorism, and crop failures, it is sometimes argued that government involvement in these insurance markets is necessary because large disasters can severely impair private insurers' capital. Because private insurers face financing frictions, it can then be difficult for customers to purchase new insurance following disasters (Anderson [1974], Gollier [1997], Froot [2001], Froot and O'Connell [2008], and Nguyen [2012]). If the government faces smaller financing frictions than private insurers, government involvement might provide risk-sharing benefits to individual households and firms. However, the incidences and severities of floods, terrorist attacks, and crop failures are likely to be largely uncorrelated with the broader macroeconomy, so social risk considerations are unlikely to play an important role in an analysis of these programs. Similarly, the fiscal costs of these insurance programs are largely uncorrelated with the outlays for other government programs, so fiscal risk considerations should be relatively unimportant.

Regulations like food and drug safety standards are also arguably neither socially nor fiscally risky. These programs may provide social benefits by alleviating asymmetric information prob-

lems between customers and firms (Akerlof [1970], Henson and Traill [1993]), benefits which are 
likely to be relatively acyclical. And the fiscal costs of providing inspections and oversight are relatively constant and, thus, unlikely to covary with the outlays on other government programs.

Similarly, public financing for basic scientific research and education is arguably to a first order neither socially nor fiscally risky. The case for these programs is that knowledge is a public good, so the returns to producing it (research) or acquiring it (education) do not accrue solely to the agent making the investment, leading to private underinvestment relative to the first best (Nelson [1959], Arrow [1962], Stiglitz [1999], Aghion, Dewatripont, and Stein [2008]). Again, these programs likely have relatively constant costs and benefits that do not meaningfully covary with the state of the economy, making social and fiscal risk considerations fairly minor.

\subsubsection{Social risk is important, but fiscal risk is not}

A second set of programs are those for which there are important social risk considerations, but where fiscal risk is minimal (i.e., $\operatorname{Cov}\left[M_{1}, W_{1}^{\prime}(q)-X_{1}^{\prime}(q)\right] \neq 0$ but $\operatorname{Cov}\left[h^{\prime}\left(\tau_{1}\right), X_{1}^{\prime}(q)\right]=$ 0), so only the first three terms in Eq. (24) will be important. Ex ante financial regulations aimed at promoting the stability of the financial system-including bank examinations, bank capital requirements, and bank liquidity requirements - arguably fall into this category. The social benefits of these financial regulations - preventing costly bank runs that would otherwise occur - are likely to accrue during recessions when household marginal utility is high (Calomiris and Gorton [1990]). However, the government outlays associated with these regulations - the costs of conducting bank examinations and monitoring compliance with capital and liquidity requirements - are likely fairly constant over time and across states and, thus, are unlikely to covary with expenditures on other programs.

\subsubsection{Fiscal risk is important, but social risk is not}

A third set of programs are those for which there are no social risk considerations, but where there are important fiscal risk considerations (i.e., $\operatorname{Cov}\left[M_{1}, W_{1}^{\prime}(q)-X_{1}^{\prime}(q)\right]=0$ but $\operatorname{Cov}\left[h^{\prime}\left(\tau_{1}\right), X_{1}^{\prime}(q)\right] \neq$ $0)$. We have not been able to think of any programs that are likely to fall into this bucket.

\subsubsection{Both social and fiscal risk are important}

The final set of programs are those with both important fiscal and social risk considerations (i.e., $\operatorname{Cov}\left[M_{1}, W_{1}^{\prime}(q)-X_{1}^{\prime}(q)\right] \neq 0$ and $\left.\operatorname{Cov}\left[h^{\prime}\left(\tau_{1}\right), X_{1}^{\prime}(q)\right] \neq 0\right)$. In this case, all five terms in Eq. (24) may be important. Within this group, programs that are social hedges but that are fiscally risky (i.e., $\operatorname{Cov}\left[M_{1}, W_{1}^{\prime}(q)-X_{1}^{\prime}(q)\right]>0$ and $\left.\operatorname{Cov}\left[h^{\prime}\left(\tau_{1}\right), X_{1}^{\prime}(q)\right]>0\right)$ seem especially common. 
Social insurance programs fall into this category. The social value of unemployment insurance is arguably high in recessions because aggregate insurance payments rise when marginal utility is high (Landais, Michaillat, and Saez [2016, 2017]). However, unemployment insurance programs are likely to be fiscally risky: when unemployment insurance payments are high, other government expenditures are likely to be high (Musgrave and Miller [1948], Auerbach and Feenberg [2000], McKay and Reis [2016]).

Similarly, financial stability programs like bank debt guarantees arguably fall into this bucket. The social value of preventing the output loss associated with bank runs primarily accrues in recessions, so these programs are social hedges. However, the outlays associated with debt guarantee programs are likely to be high at times when other government outlays are elevated.

Countercyclical stimulus programs would also fall into this group. The textbook Keynesian view is that, due to sticky nominal prices and wages, declines in aggregate demand lead output and employment to fall below their potential under flexible prices (Samuelson [1947], Romer [2001]). The traditional view is that, when output is below potential, the government should invest in "shovel-ready" public projects to stimulate aggregate demand, thus pushing the economy closer to the first-best outcome under flexible prices. In this view, countercyclical Keynesian stimulus programs are a fiscally risky, social hedge.

What these programs have in common is that they generate social benefits through the use of transfer payments. Since the need for these transfer payments is countercyclical, the programs are social hedges but are fiscally risky. And because many government programs share this feature, total government expenditures will tend to rise in bad times. Formally, these programs have the features that (i) $\operatorname{Cov}\left[M_{1}, W_{1}^{\prime}(q)-X_{1}^{\prime}(q)\right]>0$-i.e., they are social hedges and (ii) $\operatorname{Cov}\left[W_{1}^{\prime}(q)-X_{1}^{\prime}(q), X_{1}^{\prime}(q)\right]>0$-i.e., the net benefits are correlated with outlays. Since many government programs have these features, it will then typically be the case that $\operatorname{Cov}\left[h^{\prime}\left(\tau_{1}\right), X_{1}^{\prime}(q)\right]>0$-i.e., these programs will be fiscally risky. This logic also shows why it is hard to have programs that are both social and fiscal hedges. Since most social hedges (i.e., programs where $\left.\operatorname{Cov}\left[M_{1}, W_{1}^{\prime}(q)-X_{1}^{\prime}(q)\right]>0\right)$ have the feature that $\operatorname{Cov}\left[W_{1}^{\prime}(q)-X_{1}^{\prime}(q), X_{1}^{\prime}(q)\right]>$ 0 , it is hard for any of them to also have the feature that $\operatorname{Cov}\left[h^{\prime}\left(\tau_{1}\right), X_{1}^{\prime}(q)\right]<0$.

However, there are socially risky programs that are fiscal hedges. Any public good that is utilized more heavily in expansions than recessions will be "socially risky" in the sense that its net benefits primarily accrue in good times. For instance, the improvement in output associated with the interstate highway system is arguably procyclical. In addition, except for the Keynesian stimulus discussed above, outlays for these public goods are also likely to be procyclical: roads are mostly built and maintained in good times. Since outlays tend to occur in economic expansions where the overall fiscal burden is low, these programs may be fiscal hedges. 
Overall, this discussion highlights the value of our general framework for cost-benefit analysis. The framework allows one to understand how different programs should fit into the government's portfolio and how social and fiscal risk considerations influence optimal program scale. Furthermore, we argue that many large government programs fall in the final bucket and have the feature that social and fiscal risk management considerations tend to pull in opposite directions.

\section{Determinants of social and fiscal risk}

In this section, we explore how the characteristics of an individual program, the rest of the government's portfolio, and the broader macroeconomy affect considerations of social and fiscal risk. To develop these intuitions, we compute approximate solutions to the government's problem. We then compute comparative statics to highlight the determinants of social and fiscal risk.

\subsection{Approximate first-order conditions}

We replace the government's two key first-order conditions with Taylor series approximations about the expansion point $\left(C_{t}, Y_{t}, T_{t}\right)=(\bar{C}, \bar{Y}, \bar{T})$. We assume that the government program has constant returns to scale so that $W_{t}(q)=q W_{t}$ and $X_{t}(q)=q X_{t}$.

Specifically, as shown in the Appendix, we have $h^{\prime}\left(\tau_{t}\right) \approx \bar{h}^{\prime}+\bar{\eta}(\bar{T} / \bar{Y})\left(T_{t} / \bar{T}-Y_{t} / \bar{Y}\right)$ and $u^{\prime}\left(C_{t}\right) \approx 1-\gamma\left(C_{t}-\bar{C}\right)$ where $\gamma \equiv-u^{\prime \prime}(\bar{C}) / u^{\prime}(\bar{C}) \geq 0$ denotes the coefficient of absolute risk aversion at $\bar{C}$. Using these approximations, we can replace the optimality condition for $D_{0}$ in Eq. (19) with the approximate condition

$$
\begin{aligned}
& \left(1-\gamma\left(\tilde{C}_{0}-\bar{C}\right)\right)\left(\bar{h}^{\prime}+\bar{\eta} \frac{\bar{T}}{\bar{Y}}\left(\frac{T_{0}}{\bar{T}}-\frac{Y_{0}}{\bar{Y}}\right)\right) \\
= & \left(\beta \hat{R}_{f}+\beta D_{0} \delta_{D_{0}}\right) E\left[\left(1-\gamma\left(\tilde{C}_{1}-\bar{C}\right)\right)\left(\bar{h}^{\prime}+\bar{\eta} \frac{\bar{T}}{\bar{Y}}\left(\frac{T_{1}}{\bar{T}}-\frac{Y_{1}}{\bar{Y}}\right)\right)\right],
\end{aligned}
$$

where

$$
\tilde{C}_{t} \equiv Y_{t}-\left(\bar{Y} \frac{\eta}{2} \bar{\tau}^{2}+\bar{h}^{\prime}\left(T_{t}-\bar{T}\right)-\hat{\eta}_{Y}\left(Y_{t}-\bar{Y}\right)\right)+W_{t} q-X_{t} q-G_{t}
$$

is an approximation to consumption, and $\bar{\tau}, \bar{h}^{\prime}, \bar{\eta}, \hat{\eta}_{Y}, \delta_{D_{0}}$, and $\hat{R}_{f}$ are constants given in the Appendix (when $\eta=0, \bar{h}^{\prime}=\bar{\eta}=\hat{\eta}_{Y}=\delta_{D_{0}}=0$ ). Similarly, we replace the optimality condition 
for $q$ in Eq. (22) with the approximate condition

$$
\begin{aligned}
0= & \left(1-\gamma\left(\tilde{C}_{0}-\bar{C}\right)\right)\left(W_{0}-X_{0}-\left(\bar{h}^{\prime}+\bar{\eta} \frac{\bar{T}}{\bar{Y}}\left(\frac{T_{0}}{\bar{T}}-\frac{Y_{0}}{\bar{Y}}\right)\right) X_{0}\right) \\
& +\beta E\left[\left(1-\gamma\left(\tilde{C}_{1}-\bar{C}\right)\right)\left(W_{1}-X_{1}-\left(\bar{h}^{\prime}+\bar{\eta} \frac{\bar{T}}{\bar{Y}}\left(\frac{T_{1}}{\bar{T}}-\frac{Y_{1}}{\bar{Y}}\right)\right)\left(X_{1}+D_{0} \delta_{q}\right)\right)\right],
\end{aligned}
$$

where $\delta_{q}$ is a constant given in the Appendix (when $\gamma=0, \delta_{q}=0$ ).

Eqs. (25) and (27) are a system of two quadratic equations in $D_{0}$ and $q$ that can be solved in closed form to obtain optimal policies. When $\gamma>0$ and $\eta>0$, this system reduces to a quartic in $q$ that can be solved analytically. With either (i) risk-neutral households and tax distortions $(\gamma=0$ and $\eta>0)$ or (ii) risk-averse households and no tax distortions $(\gamma>0$ and $\eta=0)$, we obtain a system of two linear equations in $D_{0}$ and $q$. We use these two limiting cases below to show how risk aversion and tax distortions impact optimal program scale.

\subsection{Risk-neutral households and tax distortions $(\gamma=0$ and $\eta>0)$}

We first consider the case where households are risk-neutral $(\gamma=0)$, but government taxation is distortionary $(\eta>0)$. This case, where the government seeks to generate net benefits for households while limiting expected fiscal costs and fiscal risk, allows us to identify the key determinants of these fiscal considerations.

When $\gamma=0$ and $\eta>0$, the approximate first-order condition for $D_{0}$ in (25) collapses to

$$
\frac{T_{0}}{\bar{T}}-\frac{Y_{1}}{\bar{Y}}=E\left[\frac{T_{1}}{\bar{T}}-\frac{Y_{1}}{\bar{Y}}\right]
$$

which says that government borrowing is chosen to smooth expected tax rates over time. As shown in the Appendix, in this case Eqs. (25) and (27) form a system of two linear equations in $D_{0}$ and $q$ that can be solved to obtain:

$$
\begin{aligned}
q^{*}= & \frac{1}{\bar{\eta} / \bar{Y}} \frac{\left(W_{0}-X_{0}\right)+\beta E\left[W_{1}-X_{1}\right]}{(1+\beta)^{-1}\left(X_{0}+\beta E\left[X_{1}\right]\right)^{2}+\beta \operatorname{Var}\left[X_{1}\right]} \\
& -\frac{1}{\bar{\eta} / \bar{Y}} \frac{\bar{h}^{\prime}+\bar{\eta} \overline{\bar{Y}}\left(\frac{1}{\bar{T}} \frac{\bar{D}+\left(G_{0}+\beta E\left[G_{1}\right]\right)}{1+\beta}-\frac{1}{\bar{Y}} \frac{Y_{0}+\beta E\left[Y_{1}\right]}{1+\beta}\right)}{(1+\beta)^{-1}\left(X_{0}+\beta E\left[X_{1}\right]\right)^{2}+\beta \operatorname{Var}\left[X_{1}\right]}\left(X_{0}+\beta E\left[X_{1}\right]\right) \\
& -\frac{1}{\bar{\eta} / \bar{Y}} \frac{\beta \operatorname{Cov}\left[\bar{\eta} \overline{\bar{Y}}\left(\frac{\bar{G}}{\bar{T}}-\frac{Y_{1}}{\bar{Y}}\right), X_{1}\right]}{(1+\beta)^{-1}\left(X_{0}+\beta E\left[X_{1}\right]\right)^{2}+\beta \operatorname{Var}\left[X_{1}\right]} .
\end{aligned}
$$

The first term in Eq. (29) is proportional to the program's expected marginal net benefit, 
i.e., $\left(W_{0}-X_{0}\right)+\beta E\left[W_{1}-X_{1}\right]$. The denominator of this term is the direct deadweight costs from increasing program expenditures at the margin. These costs are increasing in the program's expected outlays, the variability of the program's outlays, and the effective degree of "fiscal risk aversion", $\bar{\eta} / \bar{Y}$, which is increasing in the labor supply elasticity with respect to the tax rate $(\eta)$ and decreasing in the tax base $(\bar{Y})$.

The second term in (29) is proportional to the expected fiscal costs of the program that arise in the presence of other government expenditures. Specifically, the numerator of the second term is equal to expected discounted marginal outlays (i.e., $X_{0}+\beta E\left[X_{1}\right]$ ) times the expected marginal deadweight cost of taxation when $q=0$.

The third term reflects the government's fiscal risk management motive and captures the additional deadweight costs that arise if time 1 spending on the program covaries positively with time 1 tax rates. Naturally, this covariance is higher when $\operatorname{Cov}\left[G_{1}, X_{1}\right]$ is larger or when $\operatorname{Cov}\left[Y_{1}, X_{1}\right]$ is smaller.

The next proposition provides a set of intuitive comparative statics, showing how the optimal scale of the project $q^{*}$ depends on the exogenous parameters of the model.

Proposition 2 Consider the case with risk-neutral households $(\gamma=0)$ and distortionary taxation $(\eta>0)$. Assume that $G_{0}+\beta E\left[G_{1}\right]>0, X_{0}+\beta E\left[X_{1}\right]>0$, and $q^{*}>0$. Then we have the following comparative statics for optimal program scale:

- $\partial q^{*} / \partial W_{0}>0, \partial q^{*} / \partial E\left[W_{1}\right]>0, \partial q^{*} / \partial X_{0}<0$, and $\partial q^{*} / \partial E\left[X_{1}\right]<0$;

- $\partial q^{*} / \partial G_{0} \propto-\left(X_{0}+\beta E\left[X_{1}\right]\right)<0$ and $\partial q^{*} / \partial E\left[G_{1}\right] \propto-\left(X_{0}+\beta E\left[X_{1}\right]\right)<0$;

- $\partial q^{*} / \partial \bar{D} \propto-\left(X_{0}+\beta E\left[X_{1}\right]\right)<0$;

- $\partial q^{*} / \partial \eta \propto-\left(\left(W_{0}-X_{0}\right)+\beta E\left[W_{1}-X_{1}\right]\right)$;

- $\partial q^{*} / \partial \operatorname{Corr}\left[X_{1}, G_{1}\right]<0, \partial q^{*} / \partial \operatorname{Corr}\left[X_{1}, Y_{1}\right]>0$, and $\partial q^{*} / \partial \operatorname{Var}\left[X_{1}\right]<0$.

These comparative statics identify the drivers of expected fiscal cost and fiscal risk in the model. For instance, the optimal scale of a program with positive expected outlays $\left(X_{0}+\right.$ $\left.\beta E\left[X_{1}\right]>0\right)$ declines with other government spending $\left(G_{0}\right.$ or $\left.E\left[G_{1}\right]\right)$. Intuitively, increasing other government spending raises the expected fiscal burden and tax distortions. By decreasing the scale of a positive-outlay program, the government can reduce the need for distortionary taxation, partially offsetting the effect of increased spending.

Similar logic applies to the effect of the severity of marginal tax distortions, $\eta . \partial q^{*} / \partial \eta$ is proportional to $-\left(\left(W_{0}-X_{0}\right)+\beta E\left[W_{1}-X_{1}\right]\right)$, so an increase in $\eta$, which increases the deadweight loss of taxation, leads the government to cut back on attractive projects with large discounted 
net benefits. When the preexisting debt burden $\bar{D}$ is high, the government should cut back on programs, particularly those with the largest expected outlays. In addition, all else equal, the government should choose a smaller scale for programs whose outlays are more variable. Finally, the government should choose a smaller scale for programs whose outlays covary positively with other spending $\left(G_{1}\right)$ or negatively with the tax base $\left(Y_{1}\right)$.

\subsection{Risk-averse households and no tax distortions $(\gamma>0$ and $\eta=0)$}

We next consider the case where households are risk-averse $(\gamma>0)$ and there are no tax distortions $(\eta=0)$. This case, where the government seeks to generate net benefits for households and to manage social risk, allows us to identify the key drivers of social risk in the model. In this case Ricardian equivalence holds, and the level of debt is not pinned down at the optimum. The approximate solution for optimal program scale is:

$$
\begin{aligned}
q^{*}= & \frac{1-\gamma\left(E\left[Y_{1}-G_{1}\right]-\bar{C}\right)}{\gamma} \frac{\left(W_{0}-X_{0}\right)+\beta E\left[W_{1}-X_{1}\right]}{\left(W_{0}-X_{0}\right)^{2}+\beta\left(E\left[W_{1}-X_{1}\right]\right)^{2}+\beta\left(\operatorname{Var}\left[W_{1}-X_{1}\right]\right)} \\
& -\frac{\left(\left(Y_{0}-G_{0}\right)-E\left[Y_{1}-G_{1}\right]\right)\left(W_{0}-X_{0}\right)}{\left(W_{0}-X_{0}\right)^{2}+\beta\left(E\left[W_{1}-X_{1}\right]\right)^{2}+\beta\left(\operatorname{Var}\left[W_{1}-X_{1}\right]\right)} \\
& -\frac{\beta \operatorname{Cov}\left[Y_{1}-G_{1}, W_{1}-X_{1}\right]}{\left(W_{0}-X_{0}\right)^{2}+\beta\left(E\left[W_{1}-X_{1}\right]\right)^{2}+\beta\left(\operatorname{Var}\left[W_{1}-X_{1}\right]\right)}
\end{aligned}
$$

The numerator of the first term in Eq. (30) is proportional to time 1 expected marginal utility when $q=0$ (i.e., $\left.1-\gamma\left(E\left[Y_{1}-G_{1}\right]-\bar{C}\right)\right)$ times expected program net benefits for risk-neutral households (i.e., $\left.\left(W_{0}-X_{0}\right)+\beta E\left[W_{1}-X_{1}\right]\right)$. The denominator captures the "income effect" that arises because the chosen level of $q$ affects the marginal utility of risk-averse households. Projects that generate large expected benefits lower marginal utility, making further projects with positive expected benefits less appealing to households.

The second term in (30) arises only when $Y_{0}-G_{0} \neq E\left[Y_{1}-G_{1}\right]$ and reflects any benefits of using the program to intertemporally smooth expected consumption between times 0 and 1 .

The final term in Eq. (30) captures the social risk management motive of smoothing consumption across states at time 1 . This risk management term is proportional to $-\operatorname{Cov}\left[Y_{1}-G_{1}, W_{1}-X_{1}\right]$ : the government likes programs that hedge against exogenous shocks, both those emanating from the private economy $\left(Y_{1}\right)$ and those emanating from other government expenditures $\left(G_{1}\right)$.

The next proposition provides a set of intuitive comparative statics, showing how the optimal scale of the project $q^{*}$ depends on the exogenous parameters of the model.

Proposition 3 Assume that $W_{0}-X_{0}>0, \beta E\left[W_{1}-X_{1}\right]>0$, and $q^{*}>0$. Then we have the 
following comparative statics for optimal program scale:

- $\partial q^{*} / \partial Y_{0} \propto-\left(W_{0}-X_{0}\right)<0, \partial q^{*} / \partial G_{0} \propto\left(W_{0}-X_{0}\right)>0, \partial q^{*} / \partial E\left[Y_{1}\right] \propto-\beta E\left[W_{1}-X_{1}\right]<0$, $\partial q^{*} / \partial E\left[G_{1}\right] \propto \beta E\left[W_{1}-X_{1}\right]>0$;

- $\partial q^{*} / \partial \gamma \propto-\left(\left(W_{0}-X_{0}\right)+\beta E\left[W_{1}-X_{1}\right]\right)<0$;

- $\partial q^{*} / \partial \operatorname{Corr}\left[W_{1}, Y_{1}\right]<0, \partial q^{*} / \partial \operatorname{Corr}\left[W_{1}, G_{1}\right]>0, \partial q^{*} / \partial \operatorname{Corr}\left[X_{1}, Y_{1}\right]>0$, and $\partial q^{*} / \partial \operatorname{Corr}\left[X_{1}, G_{1}\right]<0$.

In this Ricardian case, comparative statics with respect to the $W \mathrm{~s}$ and $X \mathrm{~s}$ are generally ambiguous due to competing substitution and income effects. For instance, the impact of program net benefits at time 0 on optimal scale is $\partial q^{*} / \partial\left(W_{0}-X_{0}\right) \propto\left(1-\gamma C_{0}\right)-\gamma q^{*}\left(W_{0}-X_{0}\right)$, which is ambiguous. Holding marginal utility fixed, an increase in $\left(W_{0}-X_{0}\right)$ leads to a substitution effect that makes the government want to do more of the program. But there is a competing income effect: the increase in $\left(W_{0}-X_{0}\right)$ reduces marginal utility and lowers the government's willingness to pay, pushing it to do less of the program.

In contrast, as the proposition states, comparative statics with respect to the $Y \mathrm{~s}$ and $G \mathrm{~s}$ will be unambiguous because they only involve income effects, which alter the government's willingness to pay for a particular program. For instance, we have $\partial q^{*} / \partial Y_{0}<0$ because the increase in $Y_{0}$ reduces marginal utility and lowers the government's willingness to pay, pushing it to do less of the program. In addition, $\partial q^{*} / \partial \gamma$ is proportional to $-\left(\left(W_{0}-X_{0}\right)+\beta E\left[W_{1}-X_{1}\right]\right)$, so an increase in risk aversion $\gamma$ leads the government to cut back on attractive projects with large discounted net benefits.

\subsection{Risk-averse households and tax distortions $(\gamma>0$ and $\eta>0)$}

The approximate solution in the general case where $\gamma>0$ and $\eta>0$ mixes the intuitions derived in the past two sections. In addition, analytically solving the system of two quadratic equations in $q$ and $D_{0}$ given by Eqs. (25) and (27) is unwieldy and adds little additional insight. Thus, to explore the interactions of social and fiscal risk in the general case where $\gamma>0$ and $\eta>0$, we use numerical solutions below.

\section{Applications}

\subsection{Single program: Government guarantees of bank debt}

In this section, we provide a full analysis of a single government program within our framework. We start with a microfoundation, then embed the program within our framework, and compute numerical comparative statics in the general case where $\gamma>0$ and $\eta>0$. 
Our example builds on Stein (2012) and Hanson, Shleifer, Stein, and Vishny (2015) and considers the value of policies to prevent economically destabilizing bank runs. In these models, banks hold long-term risky assets, which they finance by issuing equity and short-term debt. Households assign a special value to short-term bank debt because it is completely safe, but issuing uninsured short-term debt means that banks may be forced to liquidate assets in an economic downturn. These fire sales are costly for society because other savers use their scarce capital to purchase liquidated assets, instead of investing in new real projects. Since the uninsured depositors who withdraw funds from banks do not have access to the same investment opportunities, these fire sales reduce real investment. Because banks do not fully internalize these costs of short-term debt financing, there is scope for welfare-improving government intervention. ${ }^{12}$

\section{[Figure 1 here]}

Our example, depicted in Figure 1, formalizes this intuition. There are two periods $t=0$ and $t=1$ where payoffs to households are realized. In addition, there is an interim period $t=1 / 2$ where news arrives, but no payoffs are realized. At $t=0$ households derive special monetary services from holding bank debt that is completely safe. With probability $\pi$ good news arrives at $t=1 / 2$ and agents learn that there will be an economic expansion at $t=1$ and bank assets will perform well (call this state $s=H$ ). With probability $1-\pi$ agents receive bad news at $t=1 / 2$. If there is bad news at $t=1 / 2$, then with probability $\theta$ there is a moderate recession at $t=1$ and bank assets will suffer moderate losses (state $s=L H$ ). With probability $(1-\theta$ ) there will be a severe recession at $t=1$ and bank assets will be worthless (state $s=L L$ ). Thus, there are three possible states at time $1, s \in\{H, L H, L L\}$, with probabilities $\operatorname{Pr}(s=H)=\pi$, $\operatorname{Pr}(s=L H)=(1-\pi) \theta$, and $\operatorname{Pr}(s=L L)=(1-\pi)(1-\theta)$.

There are two technologies for making bank debt completely safe. First, banks can issue uninsured debt which is made safe by liquidating bank assets if bad news arrives at $t=1 / 2 .{ }^{13}$ Second, the government can insure bank debt, covering any realized shortfall between the value of bank assets and insured debt. In order to issue insured deposits, we assume the government requires banks to have enough equity capital to absorb the mild losses that arise if there is a moderate recession at time $1(s=L H)$. Thus, the government guarantee program only covers the shortfall that arises if there is a severe recession at time $1(s=L L)$. Total safe bank debt

\footnotetext{
${ }^{12}$ Of course, there are other reasons that fire sales may be costly to the economy (e.g., Diamond and Rajan 2011). The example we provide here is illustrative.

${ }^{13}$ If banks issue uninsured debt and there is bad news at $t=1 / 2$, they must liquidate assets to ensure that the debt remains completely safe. Bank assets still have a positive value at $t=1 / 2$ since with probability $\theta$ the recession will be mild and the losses on assets will also be mild. However, the assets cannot support any amount of completely safe debt since with probability $1-\theta$ there will be a severe depression and the assets will be worth 0 . Thus, to keep their uninsured debt completely safe, banks must liquidate assets following bad news at $t=1 / 2$.
} 
is $M=M_{U}+M_{I}$ where $M_{U}$ is uninsured debt and $M_{I}=m_{I} \cdot q$ is amount of bank debt that is insured by the government. Here $m_{I}>0$ and $q$ is the scale of the government's guarantee program. For simplicity, we assume that $M$ is fixed, so an expansion of government guaranteed debt crowds out uninsured debt one-for-one. Thus, the monetary services households enjoy from holding bank debt are fixed; the only question is how this debt is made safe.

Issuing uninsured bank debt is social costly because it may necessitate asset liquidations at $t=1$ that lead to a decline in real investment. Specifically, we assume that real investment at $t=1$ in state $H$ is $K$, where $K$ is some exogenous amount of savings at $t=1$. The net social returns to investment are $f \cdot K-K$, where $f>1$ is a constant. By contrast, if there is bad news at $t=1 / 2$, then real investment is $K-M_{U}=K-M+m_{I} \cdot q$. Real investment falls because (i) other savers forgo productive real investments to purchase liquidated bank assets and (ii) the depositors who withdraw funds from the bank do not have access to these same projects. Thus, the net returns to investment following bad news at $t=1 / 2$-in both states $L H$ and $L L$-is

$$
f \cdot\left(K-M_{U}\right)-\left(K-M_{U}\right)=(f-1)(K-M)+(f-1) m_{I} \cdot q,
$$

which is increasing in $q$, the scale of the government's guarantee program.

If banks issue guaranteed debt, there are no such liquidations and investment is higher. Thus, the gross social benefit of having a guarantee program of scale $q$ is that consumption is higher by $W_{1, L H}(q)=(f-1) m_{I} \cdot q$ in state $L H$ and $W_{1, L L}(q)=f m_{I} \cdot q$ in state $L L$. (There are no

social benefits of guarantees in state $\left.H: W_{1, H}(q)=0\right)$. The fiscal costs of guarantees stem from the fact that the government has to make outlays $X_{1, L L}(q)=m_{I} \cdot q$ to pay off the guaranteed debt in the severe recessionary state $L L$. (Government outlays are $X_{1, H}(q)=X_{1, L H}(q)=0$ in states $H$ and $L H$ because bank assets perform well enough so banks can fully repay the debt.)

In summary, an expansion of the debt guarantee program raises investment in both states $L H$ and $L L$, but creates costly fiscal distortions in state $L L$. We can write the social benefits and fiscal costs of this debt guarantee program at time 1 as $W_{1 s}(q)=W_{1 s} \cdot q$ and $X_{1 s}(q)=X_{1 s} \cdot q$ for states $s \in\{H, L H, L L\}$ where:

\section{[Table 1 here]}

In addition, we assume that the government charges deposit insurance premia at time 0 that are based on a risk-neutral valuation of expected guarantee payouts at $t=1$ (as it does in practice). Thus, we have $X_{0}(q)=-\beta(1-\pi)(1-\theta) m_{I} \cdot q$. Finally, we assume that debt guarantees may lower output at $t=0$ because of moral-hazard related distortions. We capture this by assuming that $W_{0}(q)=W_{0} \cdot q$ where $W_{0} \leq 0$. 


\subsubsection{Numerical solution with risk-averse households and tax distortions}

With this microfoundation, we now explore the general case where $\gamma>0$ and $\eta>0$ using numerical solutions. Our key takeaway is that the government's social risk management and fiscal risk management motives often pull in opposite directions. Which motive dominates depends on the parameters of the economy and the project.

\section{Parameter Values}

\section{[Table 2 about here]}

Table 2 lists the baseline parameters underlying our numerical example. At time 0, exogenous private income is $Y_{0}=1$ and exogenous government spending is $G_{0}=0$. The parameters governing the probabilities of the three time 1 states are $\pi=\theta=50 \%$. Thus, the $H$ state occurs with probability $\pi=50 \%$. In the $H$ state, there is an economic expansion: private income is $Y_{1 H}=1.2$ and government spending is $G_{1 H}=-0.1$. With probability $(1-\pi) \theta=25 \%$, the $L H$ state occurs. We interpret the $L H$ state as a moderate recession that leads to a rise in government spending on automatic stabilizer programs. In the $L H$ state, exogenous income is $Y_{1 L H}=0.85$, and exogenous government spending is $G_{1 L H}=0.075$. Finally, with probability $(1-\pi)(1-\theta)=25 \%$, the $L L$ state occurs. We interpret the $L L$ state as a severe recession that leads to a larger rise in government spending on automatic stabilizer programs. In the $L L$, exogenous income is $Y_{1 L L}=0.75$, and exogenous government spending is $G_{1 L L}=0.125$. Thus, we have $E\left[Y_{1}\right]=Y_{0}=1$ and $E\left[G_{1}\right]=G_{0}=0$, so the expected growth of private income and other government spending are both zero.

Three parameters control household preferences: $\beta, \gamma$, and $\bar{C}$. We set $\beta=1$, so the riskfree rate would be zero in the absence of risk aversion. We set risk aversion to $\gamma=0.25$ and $\bar{C}=1$, so that marginal utility equals one when $C_{t}=1$ and declines to 0 when $C_{t}=5$. Turning to the fiscal parameters, we set $\bar{D}=2 / 3$ - a debt-to-GDP ratio of $66.7 \%$ - to capture the case where a government faces a high accumulated fiscal burden. We set $\eta=0.15$. Thus, in the benchmark case where $T_{0}=T_{1}=0.33$, the deadweight marginal cost of public funds is roughly $\bar{h}^{\prime}=15 \% \times 30 \%=5 \%$, a conservative assumption relative to estimates in the public finance literature.

Debt guarantees require no outlays and generate no additional income in the $H$ state at time 1 , so $X_{1 H}=W_{1 H}=0$. We assume that the gross returns to investment are given by $f=2$ and that $m_{I}=0.05$. This means that in the $L H$ state at time 1 , the program also requires no outlays $\left(X_{1 L H}=0\right)$, but generates additional private income of $W_{1 L H}=0.05$. And in the $L L$ state at 
time 1 , the program requires large outlays of $X_{1 L L}=0.05$, but generates significant additional private income of $W_{1 L L}=0.1$.

Finally, we assume that the government charges insurance premia for the debt guarantee program at time 0 based on a risk-neutral valuation of time 1 guarantee payouts. Thus, the program raises revenue at time 0 equal to $X_{0}=-25 \% \times 0.05=-0.0125$. And, as a reduced form for the moral hazard distortions created by guarantees, we assume the program lowers private income at time 0 by $W_{0}=-0.0365$. Thus, we are assuming that the expected net benefits of debt guarantees are quite small: $\left(W_{0}-X_{0}\right)+\beta E\left[W_{1}-X_{1}\right]=0.001$.

\section{Baseline Optimal Policies}

\section{[Table 3 about here]}

Table 3 reports the exact optimal government policies $\left(D_{0}, q\right)$ in this example obtained from solving Eqs. (19) and (22) as in Proposition 1, assuming a quadratic utility function of the form $u\left(C_{t}\right)=C_{t}-(\gamma / 2)\left(C_{t}-\bar{C}\right)^{2}$. Table 4 reports the approximate optimal government policies $\left(D_{0}, q\right)$ in this example obtained from solving our system of quadratics given in Eqs. (25) and (27). The approximate solutions in Table 4 are close to the exact solutions in Table 3. Thus, our discussion focuses on the exact solutions in Table 3.

Panel A of Table 3 reports the optimal scale of debt guarantees $q$, Panel B reports optimal time 0 debt $D_{0}$, and Panel $C$ reports the riskfree rate $r_{f}=R_{f}-1$. The ten rows in each panel show how optimal policy varies with parameters of the economy and the program. The five columns show how policy varies with household risk aversion $(\gamma)$ and fiscal costs $(\eta)$. Specifically, column (1) reports our baseline results with $\gamma=0.25$ and $\eta=0.15$-i.e., with both risk aversion and tax distortions. Column (2) shows the risk-neutral solution with only tax distortions: $\gamma=0$ and $\eta=0.15$. Column (3) shows the Ricardian solution with $\gamma=0.25$ and $\eta=0$. Because Ricardian

equivalence holds in this case, debt is indeterminate in Panel B. Column (4) shows the effect of increasing risk-aversion relative to the baseline, setting $\gamma=0.5$ and $\eta=0.15$. Finally, column (5) shows the effect of increasing tax distortions, setting $\gamma=0.25$ and $\eta=0.175$.

We start with the results in row (1) and column (1). The optimal scale of the program in Panel $\mathrm{A}$ is $q=3.28$. Although the net benefits for risk-neutral households are small, debt guarantees are an attractive social hedge, delivering additional consumption in the $L H$ and $L L$ states when household marginal utility is high. To smooth taxes over time, Panel B shows that the government borrows $D_{0}=0.24$ at time 0 . Panel $\mathrm{C}$ shows that the risk-free rate is $4.1 \%$, reflecting the fact that marginal utility is expected to decline slightly from time 0 and 1. 
Moving across the first row, column (2) shows that optimal program scale declines when households are risk neutral: risk-neutral households have a lower willingness to pay for this social hedge. Similarly, program scale rises when there are no tax distortions in column (3). Finally, $q$ rises in column (4) when risk aversion rises to $\gamma=0.50$ and $q$ falls in column (5) when tax distortions increase to $\eta=0.175$. Taken together, the results in row (1) show that the need to manage fiscal risk can significantly reduce the government's ability to manage social risk. Specifically, when taxes are distortionary $(\eta>0)$, the government should only choose a large amount of a program if it has large net benefits in expectation $\left(\left(W_{0}-X_{0}\right)+\beta E\left[W_{1}-X_{1}\right]\right.$ is large) or if it is a strong social hedge ( $\operatorname{Cov}\left[Y_{1}-G_{1}, W_{1}-X_{1}\right]$ is large). Put differently, the distortionary costs of taxation argue in favor of fiscal conservatism, raising the hurdle that must be cleared before the government undertakes a program designed to correct a market failure.

\section{[Table 4 about here]}

Numerical Comparative Statics The remaining rows in Table 3 show how optimal policy varies with parameters of the background economy and the program. In row (2), we increase the government's accumulated deficit $\bar{D}$ from 0.667 to 0.8 . When taxation is distortionary-i.e., in all columns other than (3), this leads to a decline in optimal program scale. Intuitively, raising the government's accumulated deficit increases tax distortions. By decreasing the scale of a program with positive outlays, the government can reduce the need for distortionary taxation, partially offsetting the effect of the rise in $\bar{D}$. In this way, our model is consistent with a "fiscal austerity" logic under which a high accumulated deficit reduces the attractiveness of many government programs.

In row (3), we raise expected private income at time 1 by 0.05 in all states relative to the baseline in row (1). The rise in $E\left[Y_{1}\right]$ has two competing effects. When households are risk averse, the increase in $E\left[Y_{1}\right]$ lowers time 1 marginal utility, reducing the willingness to pay for debt guarantees. However, the increase in $E\left[Y_{1}\right]$ also lowers expected tax rates, leading to a decline in the marginal deadweight costs of taxation. This pushes the government to do more of the project. This can be see in column (2), which shows that tax distortions have an offsetting effect, so $q^{*}$ rises when households are risk neutral and taxes are distortionary.

In row (4), we make the economy riskier by raising the volatility of time 1 income by 0.05 relative to the baseline, setting $Y_{1 H}=1.25, Y_{1 L H}=0.8$, and $Y_{1 L L}=0.7$. Again, the rise in $\operatorname{Var}\left[Y_{1}\right]$ has two competing effects. Higher volatility makes debt guarantees more valuable as a social hedge, increasing the optimal program scale. However, the increase in $\operatorname{Var}\left[Y_{1}\right]$ raises the volatility of tax rates at time 1 . Since $\operatorname{Cov}\left[X_{1}, Y_{1}\right]<0$, the resulting increase in fiscal risk pushes the government to do less of the program. As above, this can be seen in column (2). 
In row (5), we increase expected government spending by 0.025 in all states at time 1 . The rise in $E\left[G_{1}\right]$ has two competing effects. When households are risk averse, this change increases expected marginal utility at time 1, pushing the government expand the program. However, when taxes are distortionary, raising $E\left[G_{1}\right]$ also increases expected taxes, pushing the government to reduce the scale of the program. Therefore, the effect on an increase in $E\left[G_{1}\right]$ is ambiguous. However, in our example, the former force outweighs the latter when $\gamma>0$ and $\eta>0$.

In row (6), we increase the volatility of time 1 government spending holding fixed the mean, setting $G_{1 H}=-0.125, G_{1 L H}=0.1$, and $G_{1 L L}=0.15$. Again, the rise in $\operatorname{Var}\left[G_{1}\right]$ works through two competing channels. When households are risk averse, more volatile government spending makes marginal utility more volatile, pushing the government to do more of the program on social risk management grounds. When taxation is distortionary, more volatile government spending increases fiscal risk, pushing the government to reduce the scale of the program. In our example, the first force outweighs the second when both $\gamma>0$ and $\eta>0$.

In row (7), we increase the expected benefits of the program, increasing benefits $W_{1}$ by 0.00025 in all states at time 1 . Although changes in $E\left[W_{1}\right]$ have competing substitution and income effects, the substitution effect dominates in our example, so optimal program scale rises with $E\left[W_{1}\right]$. In row (8), we increase the variance of the program payoffs, holding fixed the mean. Holding fixed marginal utility, the resulting substitution effect makes the program more desirable as a social hedge when households are risk averse. Again, there is a competing income effect because this change lowers expected marginal utility for a given level of $q$.

In row (9), we increase the expected time 1 program outlays. In our example, the resulting substitution effect dominates, so this change always reduces the optimal program scale. Finally, in row (10), we increase the variance of program outlays, holding fixed the mean, at time 1 . The optimal scale of the program falls. Distortionary costs are convex of function of tax revenue, so increasing the variance of taxes raises expected tax distortions, leading the government to reduce the scale of the program. By contrast, as column (3) shows, when there are no tax distortions increasing the variance of program outlays has a negligible effect on program scale.

Overall, Table 3 illustrates how the government's need to manage fiscal risk limits its capacity to manage social risk. The table also highlights the fact that the government's social risk and fiscal risk management motives often pull in opposite directions as the characteristics of the economy or the government program change.

\subsection{Portfolios of government programs}

We now extend our framework to characterize the optimal portfolio of government programs. The basic trade-offs between social and fiscal risk management remain but now acquire a portfolio 
choice flavor. Specifically, distortionary taxation and household risk aversion create interdependencies amongst otherwise unrelated programs. When taxes are distortionary, the fiscal risk of a program depends on the outlays and scale of other programs in the portfolio. Similarly, when households are risk averse, the social risk of a program depends on the net benefits and scale of other programs. As a result, programs cannot be evaluated in isolation.

Different government programs are indexed by $j=1, \ldots, J$, and we let $q_{j}$ denote the chosen scale of program $j$. For simplicity, we focus on the constant returns to scale case, so that the outlays for program $j$ at time $t$ are $q_{j} X_{t j}$ and the associated social benefits are $q_{j} W_{t j}$. Adopting the vector notation that $[\mathbf{q}]_{j}=q_{j},\left[\mathbf{x}_{t}\right]_{j}=X_{t j}$, and $\left[\mathbf{w}_{t}\right]_{j}=W_{t j}$, the first-order condition for the vector of optimal program scales $\mathbf{q}$ is

$$
\mathbf{0}=u^{\prime}\left(C_{0}\right)\left(\mathbf{w}_{0}-\mathbf{x}_{0}-h^{\prime}\left(\tau_{0}\right) \mathbf{x}_{0}\right)+\beta E\left[u^{\prime}\left(C_{1}\right)\left(\mathbf{w}_{1}-\mathbf{x}_{1}-h^{\prime}\left(\tau_{1}\right) \mathbf{x}_{1}-h^{\prime}\left(\tau_{1}\right) D_{0} \frac{\partial R_{f}}{\partial \mathbf{q}}\right)\right]
$$

where $\partial R_{f} / \partial \mathbf{q}$ is the vector analog of Eq. (17). A solution is a tuple $\left(D_{0}^{*}, \mathbf{q}^{*}\right)$ that satisfies Eqs. (19) and (32) where $\tau_{0}, \tau_{1}$, and $R_{f}$ are implicitly defined by the analogs of Eqs. (14) and (16).

To better understand how social and fiscal risk create interdependencies amongst programs, we can again approximate the first-order condition. In the risk-neutral case where $\gamma=0$ and $\eta>0$, the approximate first-order condition for the scale of program $j$ is

$$
\begin{aligned}
0= & \overbrace{\left(W_{0 j}-X_{0 j}\right)+\beta E\left[W_{1 j}-X_{1 j}\right]}^{\text {Expected net marginal benefit of program } j} \\
& -\underbrace{\left[\bar{h}^{\prime}+\bar{\eta} \frac{\bar{T}}{\bar{Y}}\left(\frac{1}{\bar{T}} \frac{\bar{D}+\left(G_{0}+\beta E\left[G_{1}\right]\right)+\sum_{k} q_{k}\left(X_{0 k}+\beta E\left[X_{1 k}\right]\right)}{1+\beta}-\frac{1}{\bar{Y}} \frac{Y_{0}+\beta E\left[Y_{1}\right]}{1+\beta}\right)\right]\left(X_{0 j}+\beta E\left[X_{1 j}\right]\right)}_{\text {Fiscal risk of program } j} \\
& -\underbrace{\beta \operatorname{Cov}\left[\bar{\eta} \frac{\bar{T}}{\bar{Y}}\left(\frac{G_{1}+\sum_{k} q_{k} X_{1 k}}{\bar{T}}-\frac{Y_{1}}{\bar{Y}}\right), X_{1 j}\right]}_{\text {Expected fiscal cost of program } j} .
\end{aligned}
$$

In the single-program case studied above, we took other government expenditures $G_{t}$ as given. Now $G_{t}$ is supplemented by the sum of expenditures on other programs in the portfolio, $\sum_{k} q_{k} X_{t k}$. Thus, the expected fiscal cost and fiscal risk of program $j$ depend on the scale of other programs in the government's portfolio. And, crucially, the desire to manage fiscal risk means that the government dislikes programs that require large outlays in states where other large-scale programs in the portfolio also require significant outlays. 
In the Ricardian case where $\gamma>0$ and $\eta=0$, the approximate first-order condition is

$$
\begin{aligned}
0= & \overbrace{\left(W_{0 j}-X_{0 j}\right)+R_{f}^{-1} E\left[W_{1 j}-X_{1 j}\right]}^{\text {Expected net benefit marginal benefit of program } j} \\
& -\underbrace{\frac{\gamma}{1-\gamma\left(\tilde{C}_{0}-\bar{C}\right)} \beta \operatorname{Cov}\left[Y_{1}-G_{1}+\sum_{k} q_{k}\left(W_{1 k}-X_{1 k}\right), W_{1 j}-X_{1 j}\right]}_{\text {Social risk of program } j} .
\end{aligned}
$$

Thus, when $\gamma>0$, the desire to manage social risk means that the government likes programs that deliver large net benefits in states where the portfolio of government programs delivers small net benefits. The interdependence that arises in the Ricardian limit of our model with risk-averse households is akin to the interdependence recently emphasized by Martin and Pindyck (2015).

\subsubsection{Optimal scale of debt guarantees versus regulation}

To illustrate these portfolio intuition, we now study how the optimal mix of debt guarantees and financial regulations varies with the extent of tax distortions and the government's preexisting fiscal commitments. We assume that both financial regulations and debt guarantees may be beneficial from a financial stability standpoint, helping to reduce the likelihood or severity of financial crises. However, they may differ in how effective they are (i.e., in the social benefits they generate in recessions) and how much fiscal risk they create.

For simplicity, we work with the risk-neutral case where $\gamma=0$ and $\eta>0$. Without loss of generality, we focus on benefits and outlays at time 1 , assuming that $W_{0 j}=0$ and $X_{0 j}=0$ for programs $j=1,2, G_{0}=E\left[G_{1}\right]=0$, and $Y_{0}=E\left[Y_{1}\right]=\bar{Y}$. To ease notation, we drop the time subscripts so that, for example, $X_{\text {reg }}$ denotes outlays associated with the regulatory program and $X_{\text {gtee }}$ denotes outlays associated with debt guarantee program at time 1 .

We assume that regulation is a fiscally safe program in the sense that outlays are constant across the three time 1 states, so $\operatorname{Var}\left[X_{r e g}\right]=0$. Regulatory outlays can be thought of as the costs of paying regulators and conducting bank examinations. As discussed above, debt guarantees are a fiscally risky program so $\operatorname{Var}\left[X_{\text {gtee }}\right]>0$ : the program incurs fiscal costs in the severe recession state at time 1. Furthermore, as before, we assume that spending on debt guarantees tends to be high in states where tax rates would otherwise be high, so $\operatorname{Cov}\left[G-\frac{\bar{T}}{\bar{Y}} Y, X_{\text {gtee }}\right]>0$. 
Using the approximation in Eq. (33), the optimal program mix satisfies:

$$
\begin{aligned}
& {\left[\begin{array}{c}
q_{\text {reg }}^{*} \\
q_{\text {gtee }}^{*}
\end{array}\right]=\frac{\left(1+\beta^{-1}\right)}{\bar{\eta} / \bar{Y}}\left(\frac{E\left[W_{r e g}-X_{r e g}\right]}{E\left[X_{r e g}\right]}-\bar{h}^{\prime}\right)\left[\begin{array}{c}
\left(E\left[X_{r e g}\right]\right)^{-1} \\
0
\end{array}\right]} \\
& +\frac{1}{\bar{\eta} / \bar{Y}} \frac{E\left[X_{\text {gtee }}\right]}{\operatorname{Var}\left[X_{\text {gtee }}\right]}\left(\frac{E\left[W_{\text {gtee }}-X_{\text {gtee }}\right]}{E\left[X_{\text {gtee }}\right]}-\frac{E\left[W_{\text {reg }}-X_{r e g}\right]}{E\left[X_{\text {reg }}\right]}\right)\left[\begin{array}{c}
-\left(E\left[X_{\text {reg }}\right]\right)^{-1} E\left[X_{\text {gtee }}\right] \\
1
\end{array}\right] \\
& -\beta^{-1} \bar{D}\left[\left(E\left[X_{r e g}\right]\right)^{-1}\right]-\frac{\operatorname{Cov}\left[G-\frac{\bar{T}}{\bar{Y}}, X_{\text {gtee }}\right]}{\operatorname{Var}\left[X_{\text {gtee }}\right]}\left[\begin{array}{c}
-\left(E\left[X_{\text {reg }}\right]\right)^{-1} E\left[X_{\text {gtee }}\right] \\
1
\end{array}\right] \text {. }
\end{aligned}
$$

The first term in Eq. (35) says that an increase in the effectiveness of regulation in generating social benefits $E\left[W_{r e g}-X_{r e g}\right] / E\left[X_{r e g}\right]$, raises $q_{r e g}^{*} \cdot{ }^{14}$ The second term in Eq. (35) says that an increase in the differential expected returns to guarantees versus regulation, $E\left[W_{\text {gtee }}-X_{\text {gtee }}\right] / E\left[X_{\text {gtee }}\right]-$ $E\left[W_{\text {reg }}-X_{\text {reg }}\right] / E\left[X_{\text {reg }}\right]$, leads the government to substitute from regulation towards guarantees. Indeed, since guarantees are fiscally risky, the government should only choose $q_{\text {gtee }}^{*}>0$ if the expected returns to guarantees are sufficiently greater than the returns to regulation. Given the desire to smooth tax rates, any substitution from regulation to guarantees is stronger when $\operatorname{Var}\left[X_{g t e e}\right]$ is small. The last two terms in Eq. (35) capture the way that background fiscal risk impacts the choices of $q_{r e g}^{*}$ and $q_{g t e e}^{*}$. The following proposition describes the behavior of the optimal mix.

Proposition 4 Suppose that $\gamma=0$ and $\eta>0$ and that regulation and debt guarantees have the characteristics assumed above. At an optimum where both $q_{\text {reg }}^{*}>0$ and $q_{\text {gtee }}^{*}>0$, we have the following comparative statics:

- $\partial q_{r e g}^{*} / \partial \operatorname{Corr}\left[G-\frac{\bar{T}}{\bar{Y}} Y, X_{\text {gtee }}\right]>0$ and $\partial q_{\text {gtee }}^{*} / \partial \operatorname{Corr}\left[G-\frac{\bar{T}}{\bar{Y}} Y, X_{\text {gtee }}\right]<0$;

- $\partial q_{g t e e}^{*} / \partial \eta \propto-\left\{E\left[W_{g t e e}-X_{g t e e}\right] / E\left[X_{g t e e}\right]-E\left[W_{\text {reg }}-X_{\text {reg }}\right] / E\left[X_{\text {reg }}\right]\right\}<0 ;$ and

$$
\begin{aligned}
\partial q_{r e g}^{*} / \partial \eta \propto & -\left(1+\beta^{-1}\right)\left\{E\left[W_{\text {reg }}-X_{\text {reg }}\right] / E\left[X_{\text {reg }}\right]\right\} \\
& +\left(\left(E\left[X_{\text {gtee }}\right]\right)^{2} / \operatorname{Var}\left[X_{\text {gtee }}\right]\right)\left\{E\left[W_{\text {gtee }}-X_{\text {gtee }}\right] / E\left[X_{\text {gtee }}\right]-E\left[W_{\text {reg }}-X_{\text {reg }}\right] / E\left[X_{\text {reg }}\right]\right\}
\end{aligned}
$$

Since taxation is distortionary, raising the correlation between spending on debt guarantees and tax rates, $\operatorname{Corr}\left[G-\frac{\bar{T}}{\bar{Y}} Y, X_{\text {gtee }}\right]$ makes guarantees less attractive and regulation more attractive. Similarly, an increase in tax distortions always leads to a reduction in the scale of the fiscally risky debt guarantee program, $\partial q_{g t e e}^{*} / \partial \eta<0$.

\footnotetext{
${ }^{14}$ The expected benefits of regulation should be thought of as net of any negative effects regulation has on growth. Since we are examining the risk-neutral case here, only the expected net benefits matters; their covariation with the state of the economy does not matter.
} 


\section{Conclusion}

Traditional public finance models have not fully incorporated the impact of risk management considerations - both social and fiscal - on optimal policy. We use insights from the literature on portfolio choice and corporate investment to develop a flexible framework for conducting cost-benefit analysis in a dynamic, stochastic environment.

We highlight the interaction between the government's social and fiscal risk management motives. These motives frequently come into conflict because programs with significant social risk management benefits often entail large government expenditures and, hence, higher tax distortions in bad times, adding to fiscal risk. Neither social risk nor fiscal risk can be judged in isolation. For example, a program's fiscal risk depends on how its outlays comove with those of other programs. As a result, government cost-benefit analysis acquires the flavor of a classic portfolio choice problem. 


\section{References}

Acharya, V., I. Drechsler, and P. Schnabl, 2014, "A Pyrrhic Victory? Bank Bailouts and Sovereign Credit Risk," Journal of Finance 69(6), 2689-2739.

Aghion, P., M. Dewatripont, and J. C. Stein, 2008, "Academic Freedom, Private-sector Focus, and the Process of Innovation," RAND Journal of Economics, 39(3), 617-635.

Aiyagari, S.R., A. Marcet, T. Sargent, and J. Seppala, 2002, "Optimal Taxation without Statecontingent Debt," Journal of Political Economy 110, 1220-1254.

Akerlof, G., 1970, "The Market for Lemons: Quality Uncertainty and the Market Mechanism," Quarterly Journal of Economics,84(3), 488-500.

Allen, F., E. Carletti, I. Goldstein, and A. Leonello, 2015, "Government Guarantees and Financial Stability," Working paper.

Anderson, D., 1974, "The National Flood Insurance Program: Problems and Potential," Journal of Risk and Insurance, 41(4), 579-599.

Arrow, K., 1962, "Economic Welfare and the Allocation of Resources for Invention," In The rate and direction of inventive activity: Economic and social factors (pp. 609-626). Princeton University Press.

Arrow, K. and R.C. Lind, 1970, "Uncertainty and the Evaluation of Public Investment Decisions," American Economic Review 60, 364-378.

Atkinson, A. B., 1990, "Pigou, Taxation, and Public Goods," Review of Economic Studies 41, 119-128.

Atkinson, A. B. and N. H. Stern, 1974, "Pigou, Taxation, and Public Goods," Review of Economic Studies 41, 119-128.

Auerbach, A. J. and D. Feenberg, 2000, "The Significance of Federal Taxes as Automatic Stabilizers," Journal of Economic Perspectives, 14(3):37-56.

Baily, M. N., 1978. "Some Aspects of Optimal Unemployment Insurance," Journal of Public Economics $10,379-402$.

Ballard, C. L. and D. Fullerton, 1992, "Distortionary Taxes and the Provision of Public Goods," Journal of Economic Perspectives 6, 117-131.

Barro, R.J., 1974, "Are Government Bonds Net Wealth?" Journal of Political Economy 82, 1095-1117.

Barro, R.J., 1979, "On the Determination of the Public Debt," Journal of Political Economy 87, 940-971.

Baumol, W. J., 1968, "On the Social Rate of Discount," American Economic Review 58, 788-802.

Bhandari, A., D. Evans, M. Golosov, and T. Sargent, 2016, "Taxes, Debts, and Redistributions with Aggregate Shocks," Working paper.

Bohn, H., 1990, "Tax Smoothing with Financial Instruments," American Economic Review 80, 12171230.

Bolton, P., H. Chen, and N. Wang, 2011, "A Unified Theory of Tobin's Q, Corporate Investment, Financing, and Risk Management," Journal of Finance 66, 1545-1578.

Bolton, P., H. Chen, and N. Wang, 2013, "Market Timing, Investment, and Risk Management," Journal of Financial Economics 109, 40-62. 
Bond, P. and I. Goldstein, 2015, "Government Intervention and Information Aggregation by Prices," Journal of Finance, 70(6): 2777-2812.

Borensztein, E. and U. Panizza, 2009, "The Costs of Sovereign Default," IMF Staff Papers 56, 683-741.

Browning, E. K., 1976, "The Marginal Cost of Public Funds," Journal of Political Economy 84, 283-298.

Brunnermeier, M. K., L. Garicano, P. Lane, M. Pagano, R. Reis, T. Santos, D. Thesmar, S. Van Nieuwerburgh, and D. Vayanos, 2016, "The Sovereign-Bank Diabolic Loop and ESBies," American Economic Review Papers and Proceedings 106, 5, 508-512.

Brunnermeier, M. K. and Y. Sannikov, 2014, "A Macroeconomic Model with a Financial Sector," American Economic Review 104, 379-421.

Campbell, J. and L. Viceira, 2002, Strategic Asset Allocation, Oxford University Press, USA.

de Faria e Castro, M., J. Martinez, and T. Philippon, 2014, "Runs versus Lemons: Fiscal Capacity and Financial Stability," Working paper.

Chetty, R., 2006, "A General Formula for the Optimal Level of Social Insurance," Journal of Public Economics 90, 1879-1901.

Dasgupta, P., S. Marglin, and A. Sen, 1972, Guidelines for Project Evaluation. New York: UNIDO, United Nations.

Diamond, D. and R. Rajan, 2011, "Fear of Fire Sales, Illiquidity Seeking, and Credit Freezes," Quarterly Journal of Economics 126(2), 557-91.

Diamond, P.A., 1998, "Optimal Income Taxation: An Example with a U-shaped Pattern of Optimal Marginal Tax Rates," American Economic Review 88, 83-95.

Diamond, P. A. and J. A. Mirrlees, 1971, "Optimal Taxation and Public Production II:Tax rules," American Economic Review 61, 261-278.

Fazzari, S.M., R. G. Hubbard, and B. C. Petersen, 1988, "Financing Constraints and Corporate Investment," Brookings Papers on Economic Activity 1, 141-195.

Froot, K.A, "The Market for Catastrophe Risk: A Clinical Examination," Journal of Financial Economics 60, no. 2-3 (2001): 529-571.

Froot, K.A. and P. O'Connell, "On the Pricing of Intermediated Risks: Theory and Application to Catastrophe Reinsurance," Journal of Banking and Finance 32, no. 1 (2008): 69-85.

Froot, K., D. Scharfstein, and J. C. Stein, 1993, "Risk Management: Coordinating Corporate Investment and Financing Policies," Journal of Finance 48, 1629-1658.

Fullerton D., 2008, "Laffer Curve," In The new Palgrave dictionary of economics. Palgrave Macmillan, London.

Geithner, T., 2014, Stress Test: Reflections on Financial Crises. Crown Publishers, New York.

Gollier, C., 1997, "About the Insurability of Catastrophic Risks," Geneva Papers on Risk and Insurance. Issues and Practice,22(83), 177-186.

Golosov, M., E. Farhi, and A. Tsyvinski, 2009, "A Theory of Liquidity and Regulation of Financial Intermediation," Review of Economic Studies 76, 973-992. 
Greenwald, B.C. and J. Stiglitz, 1986, "Externalities in Economies with Imperfect Information and Incomplete Markets," Quarterly Journal of Economics 101, 229-264.

Harberger, A. C., 1964, "The Measurement of Waste," American Economic Review 54, 58-76.

He, Z. and A. Krishnamurthy, 2013, "Intermediary Asset Pricing," American Economic Review 103, 732-770.

Henson, S. and B. Traill, 1993, "The Demand for Food Safety: Market Imperfections and the Role of Government," Food Policy, 18(2), 152-162.

Huang, C. and R. H. Litzenberger, 1988, Foundations for Financial Economics. Prentice Hall.

Kaplan, S. N. and L. Zingales, 1997, "Do Investment Cash-flow Sensitivities Provide Useful Measures of Financing Constraints?" Quarterly Journal of Economics 112, 169-215.

Kelly, B., L. Pastor, and P. Veronesi, 2016, "The Price of Political Uncertainty: Theory and Evidence from the Option Market," Journal of Finance, forthcoming.

Kreiner C.T. and N. Verdelin, 2012, "Optimal Provision of Public Goods: A Synthesis," Scandinavian Journal of Economics. 114(2): 384-408.

Landais, C., P. Michaillat, and E. Saez, 2016, "A Macroeconomic Approach to Optimal Unemployment Insurance: Theory," Working paper.

Landais, C., P. Michaillat, and E. Saez, 2017, "A Macroeconomic Approach to Optimal Unemployment Insurance: Applications," American Economic Journal: Economic Policy, forthcoming.

Leeper, E., 1991, "Equilibria under Active and Passive Monetary and Fiscal Policies," Journal of Monetary Economics 27, 129-147.

Linter, J., 1965, "The Valuation of Risk Assets and the Selection of Risky Investments in Stock Portfolios and Capital Budgets," Review of Economics and Statistics 47, 13-37.

Little, I. and J. A. Mirrlees, 1974, Project Appraisal and Planning For Developing Countries. New York: Basic Books.

Lucas, D., 2012, "Valuation of Government Policies and Projects," Annual Review of Financial Economics $4,39-58$.

Markowitz, H., 1952, "Portfolio selection," Journal of Finance 7, 77-91.

Martin, I. and R. Pindyck, 2015, "Averting Catastrophes: The Strange Economics of Scylla and Charybdis," American Economic Review 105, 2947-2985.

Mayshar, J., 1990, "On Measuring the Marginal Cost of Funds Analytically," American Economic Review 81, 1329-1335.

McClelland, R. and S. Mok, 2012, "A Review of Recent Research on Labor Supply Elasticities," Congressional Budget Office, technical report.

McKay, A. and R. Reis, 2016, "The Role of Automatic Stabilizers in the U.S. Business Cycle," Econometrica, 84(1):141-194.

Merton, R., 1973, "An Intertemporal Capital Asset Pricing Model," Econometrica 41, 867-887. 
Mirrlees, J.A., 1971, "An Exploration in the Theory of Optimum Income Taxation," Review of Economic Studies 38, 175-208.

Moss, D., 2002, When All Else Fails: Government as the Ultimate Risk Manager. Harvard University Press, Cambridge, MA.

Musgrave, R. A. and M. H. Miller, 1948, "Built-in flexibility," American Economic Review, 38(1):122128

Nelson, R., 1959, "The Simple Economics of Basic Scientific Research," Journal of Political Economy, 67(3), 297-306.

Nguyen, T., 2013, Insurability of Catastrophe Risks and Government Participation in Insurance Solutions. Geneva, Switzerland: UNISDR.

Pastor, L. and P. Veronesi, 2012, "Uncertainty about Government Policy and Stock Prices," Journal of Finance 67, 1219-1264.

Pastor, L. and P. Veronesi, 2013, "Political Uncertainty and Risk Premia," Journal of Financial Economics $110,520-545$.

Pigou, A. C., 1947, A Study in Public Finance. 3rd ed. London: Macmillan.

Ramsey, F. P., 1927, "A Contribution to the Theory of Taxation," The Economic Journal 37, 47-61.

Reinhart, C. and B. Sbrancia, 2011, "The Liquidation of Government Debt," Working paper.

Romer, D., 2001, Advanced Macroeconomics, McGraw-Hill.

Rothschild, M. and J. Stiglitz, 1976, "Equilibrium in Competitive Insurance Markets: An Essay on the Economics of Imperfect Information," Quarterly Journal of Economics 90, 629-649.

Saez, E., 2001, "Using Elasticities to Derive Optimal Income Tax Rates," Review of Economic Studies 68, 205-229.

Samuelson, P. A., 1947, Foundations of Economic Analysis. Cambridge, MA: Cambridge University Press.

Samuelson, P. A., 1954, "The Pure Theory of Public Expenditure," Review of Economics and Statistics $36,387-389$.

Sharpe, W., 1964, "Capital Asset Prices: A Theory of Market Equilibrium under Conditions of Risk," Journal of Finance 19, 425-444.

Stein, J. C., 2012, "Monetary Policy as Financial-stability Regulation," Quarterly Journal of Economics $127,57-95$.

Stiglitz, J. E., 1999, "Knowledge as a Global Public Good," Global public goods, 1(9), 308-326.

Stiglitz, J. E. and P. S. Dasgupta, 1971, "Differential Taxation, Public Goods and Economic Efficiency," Review of Economic Studies 38, 151-174.

Tobin, J., 1958, "Liquidity Preference as Behavior towards Risk," Review of Economic Studies 25, 65-86.

Weitzman, M. L., 1974, "Prices vs. Quantities," Review of Economic Studies 41, 477-491. 


\section{A Derivations and proofs}

\section{A.1 Derivation of Eq. (12)}

We have

$$
\begin{aligned}
C_{t}\left(\ell_{t}^{*}\right) & =Y_{t}\left(\ell_{t}^{*}\left(1-\tau_{t}\right)-\frac{\left(\ell_{t}^{*}-1+\eta\right)^{2}-\eta^{2}}{2 \eta}\right)+W_{t}(q)+(\text { Net trade govt bonds })_{t} \\
& =Y_{t}\left(\ell_{t}^{*}\left(1-\tau_{t}\right)-\frac{\left(\ell_{t}^{*}-1+\eta\right)^{2}-\eta^{2}}{2 \eta}\right)+W_{t}(q)+T_{t}-G_{t}-X_{t}(q) \quad[\text { by definition] } \\
& =Y_{t}\left(\ell_{t}^{*}-\frac{\left(\ell_{t}^{*}-1+\eta\right)^{2}-\eta^{2}}{2 \eta}\right)+W_{t}(q)-G_{t}-X_{t}(q) \quad\left[\text { since } T_{t}=\ell_{t}^{*} \tau_{t} Y_{t}\right] \\
& =Y_{t}\left(\left(1-\eta \tau_{t}\right)-\frac{\left(1-\eta \tau_{t}-1+\eta\right)^{2}-\eta^{2}}{2 \eta}\right)+W_{t}(q)-G_{t}-X_{t}(q) \quad\left[\text { since } \ell_{t}^{*}=1-\eta \tau_{t}\right] \\
& =Y_{t}\left(1-\frac{1}{2} \eta \tau_{t}^{2}\right)+W_{t}(q)-G_{t}-X_{t}(q) \quad[\text { simplifying]. }
\end{aligned}
$$

The second equality follows from the definition: (Net trade govt bonds) $)_{t}=T_{t}-G_{t}-X_{t}(q)$.

\section{A.2 Proof of Proposition 1}

Differentiation of Eq. (13) and substitution of the effect of changing $q$ on household consumption at times 0 and 1 as:

$$
\begin{aligned}
& \frac{\partial C_{0}}{\partial q}+\frac{\partial C_{0}}{\partial \tau_{0}} \frac{\partial \tau_{0}}{\partial q}=W_{0}^{\prime}(q)-X_{0}^{\prime}(q)-h^{\prime}\left(\tau_{0}\right) X_{0}^{\prime}(q) \\
& \frac{\partial C_{1}}{\partial q}+\frac{\partial C_{1}}{\partial \tau_{1}} \frac{\partial \tau_{1}}{\partial q}=W_{1}^{\prime}(q)-X_{1}^{\prime}(q)-h^{\prime}\left(\tau_{1}\right) X_{1}^{\prime}(q)-h^{\prime}\left(\tau_{1}\right) D_{0} \frac{\partial R_{f}}{\partial q}
\end{aligned}
$$

\section{A.3 Derivation of Eq. (24)}

To derive Eq. (24), we begin with Eq. (22) in the paper:

$$
\begin{aligned}
0= & u^{\prime}\left(C_{0}\right)\left(W_{0}^{\prime}(q)-X_{0}^{\prime}(q)-h^{\prime}\left(\tau_{0}\right) X_{0}^{\prime}(q)\right) \\
& +\beta E\left[u^{\prime}\left(C_{1}\right)\left(W_{1}^{\prime}(q)-X_{1}^{\prime}(q)-h^{\prime}\left(\tau_{1}\right) X_{1}^{\prime}(q)-h^{\prime}\left(\tau_{1}\right) D_{0} \frac{\partial R_{f}}{\partial q}\right)\right] .
\end{aligned}
$$

Let $M_{1} \equiv \beta u^{\prime}\left(C_{1}\right) / u^{\prime}\left(C_{0}\right)$ denote the representative household's stochastic discount factor and note that $R_{f}^{-1}=E\left[M_{1}\right]$ by household's Euler equation for riskless bonds (Eq. (16)). Dividing 
Eq. (22) by $u^{\prime}\left(C_{0}\right)$ and making use of the definition of $M_{1}$, we have

$$
\begin{aligned}
0= & \left(W_{0}^{\prime}(q)-X_{0}^{\prime}(q)-h^{\prime}\left(\tau_{0}\right) X_{0}^{\prime}(q)\right) \\
& +E\left[M_{1}\left(W_{1}^{\prime}(q)-X_{1}^{\prime}(q)-h^{\prime}\left(\tau_{1}\right) X_{1}^{\prime}(q)-h^{\prime}\left(\tau_{1}\right) D_{0} \frac{\partial R_{f}}{\partial q}\right)\right] \\
= & \left(W_{0}^{\prime}(q)-X_{0}^{\prime}(q)-h^{\prime}\left(\tau_{0}\right) X_{0}^{\prime}(q)\right) \\
& +R_{f}^{-1} E\left[W_{1}^{\prime}(q)-X_{1}^{\prime}(q)-h^{\prime}\left(\tau_{1}\right) X_{1}^{\prime}(q)-h^{\prime}\left(\tau_{1}\right) D_{0} \frac{\partial R_{f}}{\partial q}\right] \\
& +\operatorname{Cov}\left[M_{1},\left(W_{1}^{\prime}(q)-X_{1}^{\prime}(q)-h^{\prime}\left(\tau_{1}\right) X_{1}^{\prime}(q)-h^{\prime}\left(\tau_{1}\right) D_{0} \frac{\partial R_{f}}{\partial q}\right)\right] \\
= & \overbrace{\left(W_{0}^{\prime}(q)-X_{0}^{\prime}(q)\right)+R_{f}^{-1} E\left[W_{1}^{\prime}(q)-X_{1}^{\prime}(q)\right]}^{\text {Expected net marginal benefit }}
\end{aligned}
$$

$$
\begin{aligned}
& -\overbrace{\left(h^{\prime}\left(\tau_{0}\right) X_{0}^{\prime}(q)+R_{f}^{-1} E\left[h^{\prime}\left(\tau_{1}\right)\right] E\left[X_{1}^{\prime}(q)+D_{0} \frac{\partial R_{f}}{\partial q}\right]\right)}^{\text {Expected fiscal cost }} \\
& +\underbrace{\operatorname{Cov}\left[M_{1}, W_{1}^{\prime}(q)-X_{1}^{\prime}(q)\right]}_{\text {Social risk management }}-\underbrace{R_{f}^{-1} \operatorname{Cov}\left[h^{\prime}\left(\tau_{1}\right), X_{1}^{\prime}(q)\right]}_{\text {Fiscal risk management }} .-\underbrace{\operatorname{Cov}\left[M_{1}, h^{\prime}\left(\tau_{1}\right)\left(X_{1}^{\prime}(q)+D_{0} \frac{\partial R_{f}}{\partial q}\right)\right]}_{\text {Interaction between social and fiscal risk }} .
\end{aligned}
$$

The second equality follows from the fact that, for any $Z_{1}$, we have $E\left[M_{1} Z_{1}\right]=E\left[M_{1}\right] E\left[Z_{1}\right]+$ $\operatorname{Cov}\left[M_{1}, Z_{1}\right]=R_{f}^{-1} E\left[Z_{1}\right]+\operatorname{Cov}\left[M_{1}, Z_{1}\right]$. The third equality follows from the fact that

$$
\begin{aligned}
& R_{f}^{-1} E\left[h^{\prime}\left(\tau_{1}\right) X_{1}^{\prime}(q)+h^{\prime}\left(\tau_{1}\right) D_{0} \frac{\partial R_{f}}{\partial q}\right] \\
= & R_{f}^{-1} E\left[h^{\prime}\left(\tau_{1}\right)\right] E\left[X_{1}^{\prime}(q)+D_{0} \frac{\partial R_{f}}{\partial q}\right]+R_{f}^{-1} \operatorname{Cov}\left[h^{\prime}\left(\tau_{1}\right), X_{1}^{\prime}(q)+D_{0} \frac{\partial R_{f}}{\partial q}\right] \\
= & R_{f}^{-1} E\left[h^{\prime}\left(\tau_{1}\right)\right] E\left[X_{1}^{\prime}(q)+D_{0} \frac{\partial R_{f}}{\partial q}\right]+R_{f}^{-1} \operatorname{Cov}\left[h^{\prime}\left(\tau_{1}\right), X_{1}^{\prime}(q)\right],
\end{aligned}
$$

(note that $D_{0} \partial R_{f} / \partial q$ is a known constant at $t=0$ and does not covary with $h^{\prime}\left(\tau_{1}\right)$ ) and by rearranging.

\section{A.4 Proof of Proposition 2}

When $\gamma=0$ and $\eta>0$, the first-order condition for $D_{0}$ is

$$
\frac{T_{0}}{\bar{T}}-\frac{Y_{0}}{\bar{Y}}=E\left[\frac{T_{1}}{\bar{T}}-\frac{Y_{1}}{\bar{Y}}\right]
$$

This implies that

$$
D_{0}=\frac{\bar{D}+G_{0}-E\left[G_{1}\right]+q\left(X_{0}-E\left[X_{1}\right]\right)+\frac{\bar{T}}{\bar{Y}}\left(E\left[Y_{1}\right]-Y_{0}\right)}{1+\beta^{-1}}
$$

where $\beta^{-1}=R_{f}$ is the gross interest rate between time 0 and 1 . Thus, the government chooses $D_{0}$ to smooth expenditures $G_{t}$ and $X_{t}$ and the accumulated debt burden $\bar{D}$ across periods. The 
solution for $D_{0}$ can be substituted into the government budget constraints to obtain

$$
\begin{aligned}
T_{0} & =\frac{\bar{D}+\left(G_{0}+\beta E\left[G_{1}\right]\right)+q\left(X_{0}+\beta E\left[X_{1}\right]\right)-\beta \frac{\bar{T}}{\bar{Y}}\left(E\left[Y_{1}\right]-Y_{0}\right)}{1+\beta} \\
T_{1} & =\frac{\bar{D}+\left(G_{0}+\beta G_{1}\right)+q\left(X_{0}+\beta X_{1}\right)+\left(G_{1}-E\left[G_{1}\right]\right)+q\left(X_{1}-E\left[X_{1}\right]\right)+\frac{\bar{T}}{\bar{Y}}\left(E\left[Y_{1}\right]-Y_{0}\right)}{1+\beta} .
\end{aligned}
$$

The approximate condition for the optimal scale of the government program $q$ reduces to

$$
\begin{aligned}
0= & \left(W_{0}-X_{0}-\left(\bar{h}^{\prime}+\bar{\eta} \frac{\bar{T}}{\bar{Y}}\left(\frac{T_{0}}{\bar{T}}-\frac{Y_{0}}{\bar{Y}}\right)\right) X_{0}\right) \\
& +\beta E\left[W_{1}-X_{1}-\left(\bar{h}^{\prime}+\bar{\eta} \frac{\bar{T}}{\bar{Y}}\left(\frac{T_{1}}{\bar{T}}-\frac{Y_{1}}{\bar{Y}}\right)\right) X_{1}\right] \\
= & \overbrace{\left(W_{0}-X_{0}\right)+\beta E\left[W_{1}-X_{1}\right]}^{\text {Expected net marginal benefit }} \\
& -\underbrace{\left(\left(\bar{h}^{\prime}+\bar{\eta} \frac{\bar{T}}{\bar{Y}}\left(\frac{T_{0}}{\bar{T}}-\frac{Y_{0}}{\bar{Y}}\right)\right) X_{0}+\beta E\left[\bar{h}^{\prime}+\bar{\eta} \frac{\bar{T}}{\bar{Y}}\left(\frac{T_{1}}{\bar{T}}-\frac{Y_{1}}{\bar{Y}}\right)\right] E\left[X_{1}\right]\right)}_{\text {Fiscal risk management }} \\
& -\underbrace{\beta C \text { ov }\left[\bar{\eta} \frac{\bar{T}}{\bar{Y}}\left(\frac{T_{1}}{\bar{T}}-\frac{Y_{1}}{\bar{Y}}\right), X_{1}\right]}_{\text {Expected fiscal cost }} .
\end{aligned}
$$

To solve for $q^{*}$, we need to substitute the expressions for tax revenue into the optimality condition for $q$ and solve. First, note that

$$
\frac{T_{0}}{\bar{T}}-\frac{Y_{0}}{\bar{Y}}=\frac{1}{\bar{T}} \frac{\bar{D}+\left(G_{0}+\beta E\left[G_{1}\right]\right)+q\left(X_{0}+\beta E\left[X_{1}\right]\right)}{1+\beta}-\frac{1}{\bar{Y}} \frac{Y_{0}+\beta E\left[Y_{1}\right]}{1+\beta} .
$$

Since $T_{1}-T_{0}=\left(G_{1}-E\left[G_{1}\right]\right)+q\left(X_{1}-E\left[X_{1}\right]\right)+\frac{\bar{T}}{\bar{Y}}\left(E\left[Y_{1}\right]-Y_{0}\right)$, we have

$$
\begin{aligned}
\frac{T_{1}}{\bar{T}}-\frac{Y_{1}}{\bar{Y}} & =\left(\frac{T_{0}}{\bar{T}}-\frac{Y_{0}}{\bar{Y}}\right)+\left(\frac{T_{1}-T_{0}}{\bar{T}}-\frac{Y_{1}-Y_{0}}{\bar{Y}}\right) \\
& =\left(\frac{T_{0}}{\bar{T}}-\frac{Y_{0}}{\bar{Y}}\right)+\left(\frac{\left(G_{1}-E\left[G_{1}\right]\right)+q\left(X_{1}-E\left[X_{1}\right]\right)}{\bar{T}}-\frac{Y_{1}-E\left[Y_{1}\right]}{\bar{Y}}\right) .
\end{aligned}
$$

Solving for $q$ yields Eq. (29). Proposition 2 then follows from differentiation of Eq. (29).

\section{A.5 Proof of Proposition 3}

Since $\tilde{C}_{t}=C_{t}$, the approximate optimality condition for $q$ reduces to

$$
\begin{aligned}
0= & \left(1+\gamma \bar{C}-\gamma\left(Y_{0}-G_{0}+q\left(W_{0}-X_{0}\right)\right)\right)\left(W_{0}-X_{0}\right) \\
& +\beta E\left[\left(1+\gamma \bar{C}-\gamma\left(Y_{1}-G_{1}+q\left(W_{1}-X_{1}\right)\right)\right)\left(W_{1}-X_{1}\right)\right] .
\end{aligned}
$$

Solving for $q$ yields Eq. (30), and Proposition 3 follow from differentiation of that equation. 


\section{A.6 Proof of Proposition 4}

Differentiation of Eq. (35).

\section{B Derivation of Approximate Solutions}

First, we use a first-order Taylor approximation of the marginal deadweight cost of taxation:

$$
h^{\prime}\left(\tau_{t}\right) \approx \bar{h}^{\prime}+\bar{\eta} \frac{\bar{T}}{\bar{Y}}\left(\frac{T_{t}}{\bar{T}}-\frac{Y_{t}}{\bar{Y}}\right) .
$$

Here $\bar{T}$ and $\bar{Y}$ are the expansion points for the approximation and $\bar{h}^{\prime}$ and $\bar{\eta}$ are constants given below (when $\eta=0, \bar{h}^{\prime}=\bar{\eta}=0$ ). Thus, the marginal deadweight cost of taxation is approximately linearly increasing in the dollar value of tax revenue $T_{t}$ and approximately linearly decreasing in the dollar value of exogenous output $Y_{t}$. To derive this approximation note that, since $\tau_{t}=$ $\left(1-\sqrt{1-4 \eta T_{t} / Y_{t}}\right) /(2 \eta)$, we have

$$
h^{\prime}\left(\tau_{t}\right)=\frac{\eta \tau_{t}}{1-2 \eta \tau_{t}} \approx \bar{h}^{\prime}+\bar{\eta} \frac{\bar{T}}{\bar{Y}}\left(\frac{T_{t}}{\bar{T}}-\frac{Y_{t}}{\bar{Y}}\right)
$$

where $\bar{\tau} \equiv(1-\sqrt{1-4 \eta \bar{T} / \bar{Y}}) /(2 \eta), \bar{h}^{\prime} \equiv(\eta \bar{\tau}) /(1-2 \eta \bar{\tau})$, and $\bar{\eta} \equiv \eta /(1-2 \eta \bar{\tau})^{3}$.

Next, we approximate consumption using

$$
C_{t} \approx \tilde{C}_{t} \equiv Y_{t}-\left(\bar{Y} \eta \bar{\tau}^{2} / 2+\bar{h}^{\prime}\left(T_{t}-\bar{T}\right)-\hat{\eta}_{Y}\left(Y_{t}-\bar{Y}\right)\right)+W_{t} q-X_{t} q-G_{t}
$$

where $\bar{\tau}$ and $\hat{\eta}_{Y}$ are constant given below (when $\eta=0, \hat{\eta}_{Y}=0$ ). Again, consumption can be linearly approximated as decreasing in tax revenue $T_{t}$ and increasing in output $Y_{t}$. To derive this approximation, note that we have

$$
\eta Y_{t} \tau_{t}^{2} / 2 \approx \eta \bar{Y} \bar{\tau}^{2} / 2+\bar{h}^{\prime}\left(T_{t}-\bar{T}\right)-\hat{\eta}_{Y}\left(Y_{t}-\bar{Y}\right)
$$

where $\hat{\eta}_{Y} \equiv \bar{h}^{\prime}(\bar{T} / \bar{Y})-(\eta / 2) \bar{\tau}^{2}$ and $\lim _{\eta \rightarrow 0} \hat{\eta}_{Y}=0$.

We next approximate households' marginal utility by taking a first-order Taylor series approximation about the consumption level $\bar{C}$ that satisfies $u^{\prime}(\bar{C})=1$. Letting $\gamma \equiv-u^{\prime \prime}(\bar{C}) / u^{\prime}(\bar{C}) \geq 0$ denote the coefficient of absolute risk aversion at $C_{t}=\bar{C}$, this yields

$$
u^{\prime}\left(C_{t}\right) \approx 1-\gamma\left(C_{t}-\bar{C}\right) \approx 1-\gamma\left(\tilde{C}_{t}-\bar{C}\right)
$$

Thus, households are risk neutral when $\gamma=0$ and are risk averse when $\gamma>0 .{ }^{15}$ We restrict attention to parameters where the right-hand side is positive -i.e., where $\tilde{C}_{t}<\bar{C}+\gamma^{-1}$.

Finally, we approximate the riskless interest rate as

$$
R_{f} \approx \hat{R}_{f} \equiv \beta^{-1} \frac{1-\gamma\left(Y_{0}-\frac{\eta}{2} \bar{Y} \bar{\tau}^{2}-G_{0}-\bar{C}\right)}{1-\gamma\left(E\left[Y_{1}-\frac{\eta}{2} \bar{Y} \bar{\tau}^{2}-G_{1}\right]-\bar{C}\right)}
$$

\footnotetext{
${ }^{15}$ This approximation is exact if households have quadratic utility.
} 
time 1 tax revenues as $T_{1} \approx G_{1}+X_{1} q+\hat{R}_{f} D_{0}$, and $\partial R_{f} / \partial D_{0}$ and $\partial R_{f} / \partial q$ using the constants

$$
\begin{aligned}
\frac{\partial R_{f}}{\partial D_{0}} \approx \delta_{D_{0}} \equiv-\frac{\hat{R}_{f}^{2} \beta \gamma \bar{h}^{\prime}+\gamma \bar{h}^{\prime}}{\beta\left(1-\gamma\left(E\left[Y_{1}-\frac{\eta}{2} \bar{Y} \bar{\tau}^{2}-G_{1}\right]-\bar{C}\right)\right)+\beta \hat{R}_{f} \frac{\bar{D}}{1+\beta^{-1}} \bar{h}^{\prime} \gamma} \\
\frac{\partial R_{f}}{\partial q} \approx \delta_{q} \equiv \gamma \frac{\hat{R}_{f} \beta E\left[W_{1}-X_{1}\left(1+\bar{h}^{\prime}\right)\right]-\left(W_{0}-X_{0}\left(1+\bar{h}^{\prime}\right)\right)}{\beta\left(1-\gamma\left(E\left[Y_{1}-\frac{\eta}{2} \bar{Y} \bar{\tau}^{2}-G_{1}\right]-\bar{C}\right)\right)+\beta \hat{R}_{f} \frac{\bar{D}}{1+\beta^{-1}} \bar{h}^{\prime} \gamma} .
\end{aligned}
$$


Figure 1: Example government program: Bank debt guarantees. The example government program is a bank debt guarantee program that creates financial stability benefits following the arrival of bad news.

\section{Time $t=0$}

Banks purchase risky assets and issue risky equity and safe debt-either insured on uninsured—-to households
Time $t=1 / 2$

Bad news arrives with probability $1-\pi$.

Insured debt is safe because the government guarantees payment in

state $L L$ at time 1 .

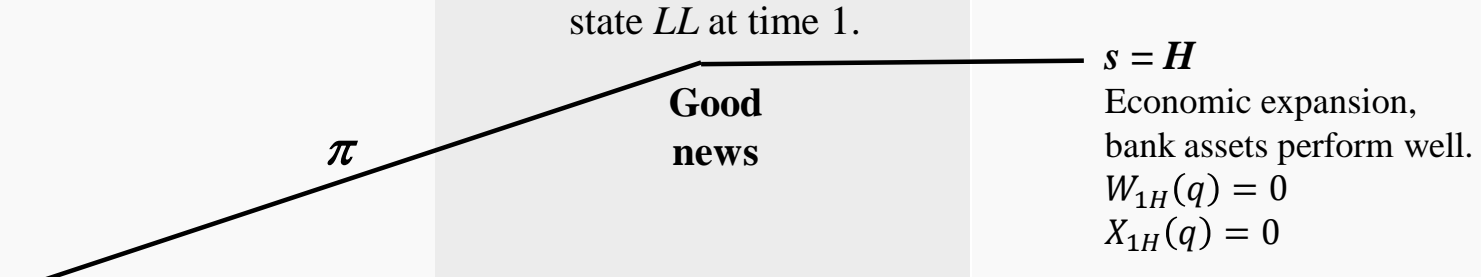
insurance premium for providing debt guarantees: $X_{0}(q)=-\beta(1-\pi)(1-\theta) m_{I} \cdot q$.

Government debt guarantees may create moral hazard: $W_{0}(q)=W_{0} \cdot q, W_{0} \leq 0$.

Time $t=1$

Payoff on risky asset revealed. Payoff on claims issued to households also revealed.
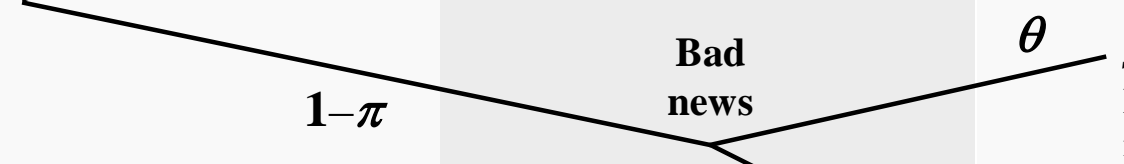

$=L H$

Mild recession, modest asset losses.

Government collects an $W_{1 L H}(q)=(f-1) m_{I} \cdot q$ $X_{1 L H}(q)=0$ If there is bad news, uninsured debt is made safe by liquidating assets at a fire-sale price.

These liquidations lead to costly underinvestment.

$s=L L$

Severe recession, assets are worthless. $W_{1 L L}(q)=f m_{I} \cdot q$ $X_{1 L L}(q)=m_{I} \cdot q$ 
Table 1: Costs and benefits in bank debt guarantee example. This table presents the costs and benefits of a bank debt guarantee program that creates financial stability benefits following the arrival of bad news. $s$ is the state of the world realized at time $\mathrm{t}=1, X_{1 s}$ is the fiscal cost of the program in state $s$, and $\mathrm{W}_{1 s}$ is the social benefit of the program in state $s$.

\begin{tabular}{lllll}
\hline \hline$S$ & $\operatorname{Pr}(s)$ & $X_{1 s}$ & $W_{1 s}$ & $W_{1 s}-X_{1 s}$ \\
\hline$H$ & $\pi$ & 0 & 0 & 0 \\
$L H$ & $(1-\pi) \theta$ & 0 & $(f-1) m_{I}$ & $(f-1) m_{I}$ \\
$L L$ & $(1-\pi)(1-\theta)$ & $m_{I}$ & $f m_{I}$ & $(f-1) m_{I}$ \\
\hline \hline
\end{tabular}


Table 2: Model parameters for the numerical example. This table presents the baseline model parameters that we use in our numerical example. The example government program is a bank debt guarantee program that creates financial stability benefits following the arrival of bad news.

\begin{tabular}{|c|c|c|}
\hline Parameter & Description & Value \\
\hline \multicolumn{3}{|c|}{ Background economy } \\
\hline$Y_{0}$ & Private income at time 0 & 1 \\
\hline$G_{0}$ & Other government spending at time 0 & 0 \\
\hline$\pi$ & Probability of the $H$ state at time 1 & $50 \%$ \\
\hline$\theta$ & Probability of a recovery following bad news at time $1 / 2$ & $50 \%$ \\
\hline$Y_{1 H}$ & Private income in $H$ state at time 1 & 1.2 \\
\hline$G_{1 H}$ & Other government spending in $H$ state at time 1 & -0.1 \\
\hline$Y_{1 L H}$ & Private income in $L H$ state at time 1 & 0.85 \\
\hline$G_{1 L H}$ & Other government spending in $L H$ state at time 1 & 0.075 \\
\hline$Y_{1 L L}$ & Private income in $L L$ state at time 1 & 0.75 \\
\hline$G_{1 L L}$ & Other government spending in $L L$ state at time 1 & 0.125 \\
\hline \multicolumn{3}{|c|}{ Household preferences } \\
\hline$\beta$ & Discount factor due to household time preference & 1 \\
\hline$\gamma$ & Household risk aversion & 0.25 \\
\hline $\bar{C}$ & Baseline level of consumption & 1 \\
\hline \multicolumn{3}{|c|}{ Fiscal parameters } \\
\hline$\eta$ & Parameter governing tax distortions & 0.15 \\
\hline $\bar{D}$ & Initial accumulated debt & 0.667 \\
\hline \multicolumn{3}{|c|}{ Government program under consideration } \\
\hline$W_{0}$ & Additional private income at time 0 & -0.0365 \\
\hline$X_{0}$ & Additional government spending at time 0 & -0.0125 \\
\hline$W_{1 H}$ & Additional private income in $H$ state at time 1 & 0 \\
\hline$X_{1 H}$ & Additional government spending in $H$ state at time 1 & 0 \\
\hline$W_{1 L H}$ & Additional private income in $L H$ state at time 1 & 0.05 \\
\hline$X_{1 L H}$ & Additional government spending in $L H$ state at time 1 & 0 \\
\hline$W_{1 L L}$ & Additional private income in $L L$ state at time 1 & 0.1 \\
\hline$X_{1 L L}$ & Additional government spending in $L L$ state at time 1 & 0.05 \\
\hline
\end{tabular}


Table 3: Optimal fiscal policies in numerical example. This table illustrates optimal fiscal policies in our numerical example. The example government program is a bank debt guarantee program that creates financial stability benefits following the arrival of bad news. The ten rows show how optimal policy varies with parameters of the background economy and the program under consideration. The five columns show how optimal policy varies with household risk aversion $(\gamma)$ and fiscal costs $(\eta)$.

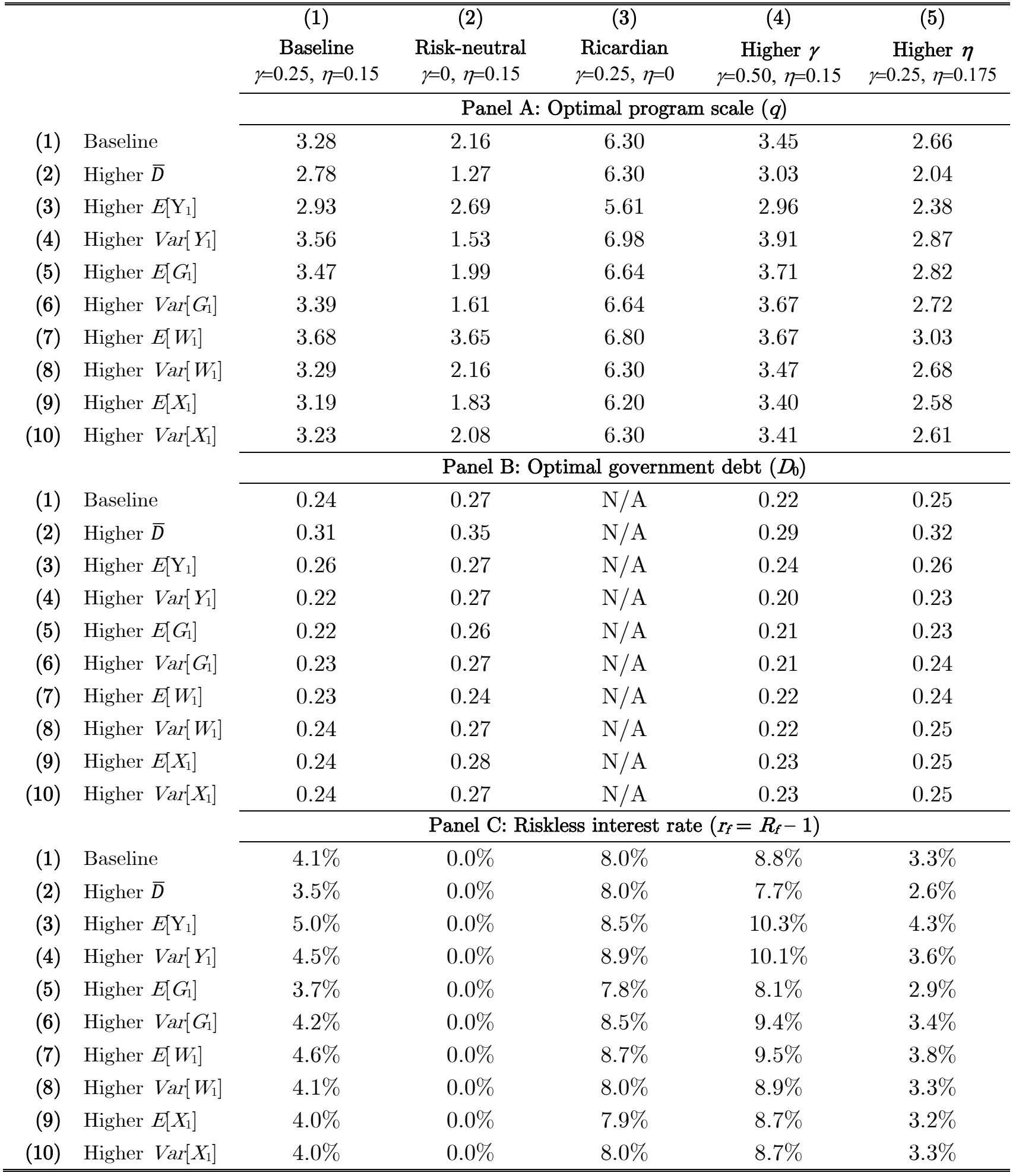


Table 4: Approximate optimal fiscal policies in numerical example. This table illustrates optimal fiscal policies in our numerical example. The example government program is a bank debt guarantee program that creates financial stability benefits following the arrival of bad news. The ten rows show how optimal policy varies with parameters of the background economy and the program under consideration. The five columns show how optimal policy varies with household risk aversion $(\gamma)$ and fiscal costs $(\eta)$.

\begin{tabular}{|c|c|c|c|c|c|c|}
\hline & & $\overline{(1)}$ & (2) & $\overline{(3)}$ & $\overline{(4)}$ & $\overline{(5)}$ \\
\hline & & $\begin{array}{c}\text { Baseline } \\
\gamma=0.25, \eta=0.15\end{array}$ & $\begin{array}{c}\text { Risk-neutral } \\
\gamma=0, \eta=0.15\end{array}$ & $\begin{array}{c}\text { Ricardian } \\
\gamma=0.25, \eta=0\end{array}$ & $\begin{array}{c}\text { Higher } \gamma \\
\gamma=0.50, \eta=0.15\end{array}$ & $\begin{array}{c}\text { Higher } \eta \\
\gamma=0.25, \eta=0.175\end{array}$ \\
\hline & & \multicolumn{5}{|c|}{ Panel A: Optimal program scale $(q)$} \\
\hline$(1)$ & Baseline & 3.82 & 4.62 & 6.30 & 3.73 & 3.33 \\
\hline$(2)$ & Higher $\bar{D}$ & 3.58 & 4.62 & 6.30 & 3.46 & 3.05 \\
\hline (3) & Higher $E\left[\mathrm{Y}_{1}\right]$ & 3.27 & 4.62 & 5.61 & 3.12 & 2.81 \\
\hline (4) & Higher $\operatorname{Var}\left[Y_{1}\right]$ & 4.30 & 4.18 & 6.98 & 4.30 & 3.77 \\
\hline (5) & Higher $E\left[G_{1}\right]$ & 4.09 & 4.62 & 6.64 & 4.03 & 3.58 \\
\hline (6) & Higher $\operatorname{Var}\left[G_{1}\right]$ & 3.99 & 3.95 & 6.64 & 3.98 & 3.47 \\
\hline (7) & Higher $E\left[W_{1}\right]$ & 4.26 & 7.17 & 6.80 & 3.96 & 3.76 \\
\hline (8) & Higher $\operatorname{Var}\left[W_{1}\right]$ & 3.83 & 4.62 & 6.30 & 3.74 & 3.35 \\
\hline (9) & Higher $E\left[X_{1}\right]$ & 3.72 & 4.08 & 6.20 & 3.68 & 3.24 \\
\hline \multirow[t]{2}{*}{$(10)$} & Higher $\operatorname{Var}\left[X_{1}\right]$ & 3.78 & 4.47 & 6.30 & 3.69 & 3.28 \\
\hline & & \multicolumn{5}{|c|}{ Panel B: Optimal government debt $\left(D_{0}\right)$} \\
\hline$(1)$ & Baseline & 0.29 & 0.28 & $\mathrm{~N} / \mathrm{A}$ & 0.29 & 0.29 \\
\hline$(2)$ & Higher $\bar{D}$ & 0.36 & 0.34 & $\mathrm{~N} / \mathrm{A}$ & 0.36 & 0.36 \\
\hline$(3)$ & Higher $E\left[\mathrm{Y}_{1}\right]$ & 0.30 & 0.28 & $\mathrm{~N} / \mathrm{A}$ & 0.30 & 0.30 \\
\hline$(4)$ & Higher $\operatorname{Var}\left[Y_{1}\right]$ & 0.28 & 0.28 & $\mathrm{~N} / \mathrm{A}$ & 0.28 & 0.29 \\
\hline$(5)$ & Higher $E\left[G_{1}\right]$ & 0.27 & 0.26 & $\mathrm{~N} / \mathrm{A}$ & 0.28 & 0.28 \\
\hline (6) & Higher $\operatorname{Var}\left[G_{1}\right]$ & 0.28 & 0.28 & $\mathrm{~N} / \mathrm{A}$ & 0.28 & 0.29 \\
\hline (7) & Higher $E\left[W_{1}\right]$ & 0.28 & 0.24 & $\mathrm{~N} / \mathrm{A}$ & 0.29 & 0.29 \\
\hline$(8)$ & Higher $\operatorname{Var}\left[W_{1}\right]$ & 0.29 & 0.28 & $\mathrm{~N} / \mathrm{A}$ & 0.29 & 0.29 \\
\hline$(9)$ & Higher $E\left[X_{1}\right]$ & 0.29 & 0.28 & $\mathrm{~N} / \mathrm{A}$ & 0.29 & 0.29 \\
\hline (10) & Higher $\operatorname{Var}\left[X_{1}\right]$ & 0.29 & 0.28 & $\mathrm{~N} / \mathrm{A}$ & 0.29 & 0.29 \\
\hline
\end{tabular}

